\title{
Automated Mini-Column Solid-Phase Extraction Cleanup for High-Throughput Analysis of Chemical Contaminants in Foods by Low-Pressure Gas Chromatography-Tandem Mass Spectrometry
}

\author{
Steven J. Lehotay ${ }^{1} \cdot$ Lijun Han $^{1,2} \cdot$ Yelena Sapozhnikova $^{1}$
}

Received: 8 April 2016 / Accepted: 24 May 2016 / Published online: 13 June 2016

(C) The Author(s) 2016. This article is published with open access at Springerlink.com

\begin{abstract}
This study demonstrated the application of an automated high-throughput mini-cartridge solid-phase extraction (mini-SPE) cleanup for the rapid low-pressure gas chromatography-tandem mass spectrometry (LPGCMS/MS) analysis of pesticides and environmental contaminants in QuEChERS extracts of foods. Cleanup efficiencies and breakthrough volumes using different mini-SPE sorbents were compared using avocado, salmon, pork loin, and kale as representative matrices. Optimum extract load volume was $300 \mu \mathrm{L}$ for the $45 \mathrm{mg}$ mini-cartridges containing 20/12/12/1 (w/w/w/w) anh. $\mathrm{MgSO}_{4} / \mathrm{PSA}$ (primary secondary amine $) / \mathrm{C}_{18} /$ CarbonX sorbents used in the final method. In method validation to demonstrate high-throughput capabilities and performance results, 230 spiked extracts of 10 different foods (apple, kiwi, carrot, kale, orange, black olive, wheat grain, dried basil, pork, and salmon) underwent automated mini-SPE cleanup and analysis over the
\end{abstract}

Mention of brand or firm name does not constitute an endorsement by the US Department of Agriculture above others of a similar nature not mentioned. USDA is an equal opportunity provider and employer.

Published in the topical collection 5th Latin American Pesticide Residue Workshop with guest editor Steven J. Lehotay.

Electronic supplementary material The online version of this article (doi:10.1007/s10337-016-3116-y) contains supplementary material, which is available to authorized users.

Steven J. Lehotay

steven.lehotay@ars.usda.gov

1 US Department of Agriculture, Agricultural Research Service, Eastern Regional Research Center, 600 East Mermaid Lane, Wyndmoor, PA 19038, USA

2 College of Science, China Agricultural University, Beijing 100193, China course of 5 days. In all, 325 analyses for 54 pesticides and 43 environmental contaminants ( 3 analyzed together) were conducted using the 10 min LPGC-MS/MS method without changing the liner or retuning the instrument. Merely, $1 \mathrm{mg}$ equivalent sample injected achieved $<5 \mathrm{ng} \mathrm{g}^{-1} \mathrm{lim}$ its of quantification. With the use of internal standards, method validation results showed that 91 of the 94 analytes including pairs achieved satisfactory results (70-120\% recovery and RSD $\leq 25 \%$ ) in the 10 tested food matrices $(n=160)$. Matrix effects were typically less than $\pm 20 \%$, mainly due to the use of analyte protectants, and minimal human review of software data processing was needed due to summation function integration of analyte peaks. This study demonstrated that the automated mini-SPE + LPGCMS/MS method yielded accurate results in rugged, highthroughput operations with minimal labor and data review.

Keywords High-throughput automation · Solid-phase extraction cleanup · Pesticide residue analysis . QuEChERS sample preparation · Fast GC-MS/MS . Analyte protectants $\cdot$ Environmental contaminants · Foods

\section{Introduction}

Trade of food products continues to increase globally [1], which is leading to greater food safety concerns $[2,3]$, and recent legislation [4] places greater emphasis on a higher rate of monitoring by private as well as regulatory laboratories to test for pesticide residues and other contaminants in the commodities. However, the cost of monitoring adds to the price of the food to the consumer, and delays in the analysis of perishable items reduces shelf life and sales of the product. Yet, more pesticides are being registered monthly for different crops worldwide [5], while human health and 
ecotoxicological risk assessment studies lead to frequent modifications of maximum residue limits (MRLs) [6], which places great demands on labs and methods to achieve high quality results, including analyte identification [7] of an ever expanding scope of ultra-trace contaminants in diverse, complicated food matrices. High economic, legal, and health risks are at stake, and the goal of the routine monitoring lab is to provide accurate results in the most efficient (cost-effective, high-throughput, automated) process possible.

Streamlined sample preparation with approaches such as QuEChERS (quick, easy, cheap, effective, rugged, and safe) $[8,9]$, and expanding scope of analytes to include environmental and emerging contaminants as well as pesticides [10], provides value in both higher sample throughput and savings by performing fewer methods for the same samples. Automation of sample cleanup conducted in parallel with the analytical step typically decreases labor, improves precision, and yields higher sample throughput. As a result, a number of different robotic instruments and approaches are available for automated sample preparation in food analysis applications [11].

Morris and Schriner [12] described an automated mini-cartridge solid-phase extraction (mini-SPE) cleanup approach called "instrument top sample preparation" (ITSP). They developed and demonstrated automated miniSPE of QuEChERS extracts for liquid chromatographytandem mass spectrometry (LC-MS/MS) analysis of 263 pesticide analytes in avocado, citrus and buttercup squash [12]. Cartridge-based SPE (c-SPE) usually provides better cleanup than dispersive-SPE (d-SPE) that is often incorporated in QuEChERS sample preparation [9]. In manual batch applications, d-SPE is usually cheaper, easier, and faster than traditional c-SPE, especially filter-vial d-SPE which conveniently cleans and filters extracts in autosampler vials [13]. However, online SPE techniques that perform cleanup at the same time as the analytical step have the added potential to reduce analyte degradation possible in batch operations when many hours can pass before final extracts are analyzed in long sequences.

Ultrahigh-performance (UHP) LC-MS/MS usually takes about 10-15 min for analysis of hundreds of analytes $[14,15]$, but conventional gas chromatography (GC)-MS/ (MS) commonly entails 25-50 min per sample [16]. However, low-pressure (LP) GC-MS(/MS) only takes $10 \mathrm{~min}$ per analysis of the same number of analytes with an acceptably small loss of separation efficiency, while providing increased sample capacity, sensitivity, and ruggedness [17]. In high-throughput analyses involving both LC- and GCamenable analytes, the sample throughput is limited by the slower method, and LPGC-MS/MS is fast enough to keep pace with UHPLC-MS/MS [18].

The aim of this study was to evaluate, optimize, and validate automated mini-SPE cleanup of QuEChERS extracts, and demonstrate the feasibility of the robotic sample preparation coupled with fast LPGC-MS/MS using analyte protectants and summation function integration to provide high-throughput monitoring of pesticides and other residues in foods with minimal human involvement. A stateof-the-art GC-MS/MS was used to reduce the amount of equivalent sample injected and extend maintenance-free operation of the instrument while still meeting $<10 \mathrm{ng} \mathrm{g}^{-1}$ quantification limit requirements.

\section{Experimental}

\section{Chemicals and Materials}

HPLC-grade acetonitrile (MeCN) was purchased from Fisher Scientific (Pittsburgh, PA; USA) and deionized water of $18.2 \mathrm{M} \Omega$-cm came from a Barnstead/Thermolyne (Dubuque, IA; USA) E-Pure Model D4641. Ammonium formate $\left(\mathrm{HCO}_{2} \mathrm{NH}_{4}\right)$ was purchased from Sigma-Aldrich (Saint Louis, MO; USA). Pesticide standards were obtained from the Environmental Protection Agency's National Pesticide Repository (Fort Meade, MD; USA), ChemService (West Chester, PA; USA), or Dr. Ehrenstorfer GmbH (Augsburg; Germany). Standards of 14 flame retardants (FRs), 14 polychlorinated biphenyls (PCBs), and 15 polycyclic aromatic hydrocarbons (PAHs) were purchased from Sigma-Aldrich, AccuStandard (New Haven, CT; USA), and Santa Cruz Biotechnology (Santa Cruz, CA; USA). Table 1 lists all the analytes in the different categories (pesticides, FRs, PCBs, and PAHs).

A working standard of the 97 pesticides and environmental contaminants was prepared at $5 \mathrm{ng} \mu \mathrm{L}^{-1}\left(0.5 \mathrm{ng} \mu \mathrm{L}^{-1}\right.$ for $\mathrm{PCBs}$ ) in $\mathrm{MeCN}$ solution. This mixed standard served as the highest level spiking solution $\left(100 \mathrm{ng} \mathrm{mL}^{-1}\right.$ in extracts), and it was also used to prepare the $2.5,1.25$, and

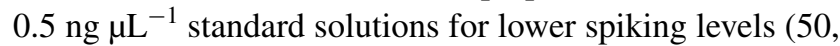
25 , and $10 \mathrm{ng} \mathrm{mL}^{-1}$, respectively).

For use as internal standards (IS), atrazine- $d_{5}$ and fenthion- $d_{6}$ were from $\mathrm{C} / \mathrm{D} / \mathrm{N}$ Isotopes (Pointe-Claire, Quebec; Canada). ${ }^{13} \mathrm{C}_{12}$-PCB 153 and a PAH mixture of acenaphthylene- $d_{8}$, benzo[a]pyrene- $d_{12}$, benzo[g,h,i]perylene$d_{12}$, fluoranthene- $d_{10}$, naphthalene- $d_{8}$, phenanthrene- $d_{10}$, and pyrene- $d_{10}$ were purchased from Cambridge Isotope Laboratories (Andover, MA; USA). Another IS, 5'-fluoro3,3',4,4',5-pentabromodiphenyl ether (FBDE 126), was obtained from AccuStandard. The IS mixture solution was prepared in $\mathrm{MeCN}$ solution at $5 \mathrm{ng} \mu \mathrm{L}^{-1}$ except $0.5 \mathrm{ng} \mu \mathrm{L}^{-1}$ for ${ }^{13} \mathrm{C}_{12}$ PCB 153 .

Analyte protectants (APs) [19] containing $25 \mathrm{mg} \mathrm{mL}^{-1}$ ethylglycerol, $2.5 \mathrm{mg} \mathrm{mL}^{-1}$ each of gulonolactone and d-sorbitol, and $1.25 \mathrm{mg} \mathrm{mL}^{-1}$ shikimic acid (all from Sigma-Aldrich) was prepared in $3 / 2(\mathrm{v} / \mathrm{v}) \mathrm{MeCN} /$ water 
Table 1 Parameters in LPGC-MS/MS analysis of the 94 analytes including three pairs ( $C E$ collision energy)

\begin{tabular}{|c|c|c|c|c|c|c|c|c|}
\hline Nos. & Analyte & $\begin{array}{l}\text { MS/MS } \\
\text { segment }\end{array}$ & $t_{\mathrm{R}}(\min )$ & $\begin{array}{l}\text { Quantifier } \\
\text { ion }(m / z)\end{array}$ & $\mathrm{CE}(\mathrm{V})$ & $\begin{array}{l}\text { Qualifier } \\
\text { ion }(m / z)\end{array}$ & $\mathrm{CE}(\mathrm{V})$ & $\begin{array}{l}\text { Internal } \\
\text { standard (IS) }\end{array}$ \\
\hline \multicolumn{9}{|c|}{ Pesticides } \\
\hline 1 & Acephate & 2 & 3.275 & $136 \rightarrow 42$ & 10 & $136 \rightarrow 94$ & 10 & Atrazine- $d_{5}$ \\
\hline 2 & Aldrin & 4 & 4.600 & $263 \rightarrow 193$ & 40 & $263 \rightarrow 228$ & 20 & Atrazine- $d_{5}$ \\
\hline 3 & Atrazine & 3 & 3.999 & $215 \rightarrow 200$ & 10 & $215 \rightarrow 138$ & 10 & Atrazine- $d_{5}$ \\
\hline 4 & Bifenthrin & 7,8 & 5.479 & $181 \rightarrow 165$ & 30 & $181 \rightarrow 166$ & 15 & Atrazine- $d_{5}$ \\
\hline 5 & Carbofuran & 3 & 3.985 & $164 \rightarrow 103$ & 25 & $164 \rightarrow 149$ & 5 & Atrazine- $d_{5}$ \\
\hline 6 & Carbophenothion & 6 & 5.259 & $342 \rightarrow 157$ & 5 & $157 \rightarrow 75$ & 40 & Atrazine- $d_{5}$ \\
\hline 7 & Chlorothalonil & 3 & 4.220 & $266 \rightarrow 133$ & 40 & $266 \rightarrow 168$ & 25 & Atrazine- $d_{5}$ \\
\hline 8 & Chlorpyrifos & 4 & 4.581 & $199 \rightarrow 171$ & 20 & $314 \rightarrow 258$ & 20 & Atrazine- $d_{5}$ \\
\hline 9 & Coumaphos & 8,9 & 5.890 & $362 \rightarrow 109$ & 15 & $362 \rightarrow 81$ & 40 & Atrazine- $d_{5}$ \\
\hline 10 & Cyfluthrin $^{\mathrm{a}}$ & 8 & 5.857 & $163 \rightarrow 127$ & 5 & $163 \rightarrow 91$ & 15 & Atrazine- $d_{5}$ \\
\hline 11 & Cypermethrin $^{a}$ & 9 & 6.043 & $181 \rightarrow 152$ & 20 & $163 \rightarrow 91$ & 15 & Atrazine- $d_{5}$ \\
\hline 12 & Cyprodinil & 4 & 4.712 & $224 \rightarrow 208$ & 25 & $224 \rightarrow 197$ & 25 & Atrazine- $d_{5}$ \\
\hline 13 & $o, p^{\prime}-\mathrm{DDE}$ & 4 & 4.867 & $246 \rightarrow 176$ & 35 & $318 \rightarrow 248$ & 25 & Atrazine- $d_{5}$ \\
\hline 14 & $p, p^{\prime}$-DDE & 5 & 5.004 & $246 \rightarrow 176$ & 35 & $318 \rightarrow 248$ & 25 & Atrazine- $d_{5}$ \\
\hline 15 & Deltamethrin $^{\mathrm{a}}$ & 8,9 & 6.435 & $181 \rightarrow 152$ & 25 & $181 \rightarrow 127$ & 25 & Atrazine- $d_{5}$ \\
\hline 16 & Diazinon & 3 & 4.111 & $179 \rightarrow 137$ & 20 & $304 \rightarrow 179$ & 15 & Atrazine- $d_{5}$ \\
\hline 17 & Dicrotophos & 2 & 3.828 & $127 \rightarrow 109$ & 10 & $127 \rightarrow 95$ & 15 & Atrazine- $d_{5}$ \\
\hline 18 & Dimethoate & 3 & 3.978 & $93 \rightarrow 63$ & 5 & $125 \rightarrow 93$ & 15 & Atrazine- $d_{5}$ \\
\hline 19 & Diphenylamine & 2 & 3.736 & $169 \rightarrow 168$ & 10 & $169 \rightarrow 140$ & 40 & Atrazine- $d_{5}$ \\
\hline 20 & Endosulfan I & 4 & 4.956 & $241 \rightarrow 206$ & 15 & $241 \rightarrow 170$ & 30 & Atrazine- $d_{5}$ \\
\hline 21 & Endosulfan II & 5,6 & 5.165 & $241 \rightarrow 206$ & 15 & $241 \rightarrow 170$ & 30 & Atrazine- $d_{5}$ \\
\hline 22 & Endosulfan sulfate & 6,7 & 5.323 & $387 \rightarrow 253$ & 15 & $387 \rightarrow 206$ & 30 & Atrazine- $d_{5}$ \\
\hline 23 & Esfenvalerate $^{a}$ & 9 & 6.259 & $167 \rightarrow 125$ & 5 & $167 \rightarrow 89$ & 35 & Atrazine- $d_{5}$ \\
\hline 24 & Ethalfluralin & 2,3 & 3.771 & $276 \rightarrow 202$ & 15 & $276 \rightarrow 105$ & 25 & Atrazine- $d_{5}$ \\
\hline 25 & Ethoprop & 2 & 3.749 & $242 \rightarrow 158$ & 5 & $242 \rightarrow 127$ & 10 & Atrazine- $d_{5}$ \\
\hline 26 & Fenpropathrin & 7,8 & 5.493 & $181 \rightarrow 152$ & 20 & $181 \rightarrow 77$ & 40 & Atrazine- $d_{5}$ \\
\hline 27 & Fipronil & 4 & 4.751 & $367 \rightarrow 213$ & 35 & $367 \rightarrow 255$ & 20 & Atrazine- $d_{5}$ \\
\hline 28 & Flutriafol & 4,5 & 4.954 & $219 \rightarrow 123$ & 20 & $219 \rightarrow 95$ & 40 & Atrazine- $d_{5}$ \\
\hline 29 & Heptachlor & 4 & 4.430 & $272 \rightarrow 237$ & 20 & $272 \rightarrow 117$ & 35 & Atrazine- $d_{5}$ \\
\hline 30 & Heptachlor epoxide & 4 & 4.775 & $353 \rightarrow 263$ & 15 & $353 \rightarrow 253$ & 25 & Atrazine- $d_{5}$ \\
\hline 31 & Heptenophos & 2 & 3.611 & $124 \rightarrow 89$ & 10 & $124 \rightarrow 63$ & 35 & Atrazine- $d_{5}$ \\
\hline 32 & Hexachlorobenzene (HCB) & 3 & 3.981 & $284 \rightarrow 214$ & 35 & $284 \rightarrow 249$ & 20 & Atrazine- $d_{5}$ \\
\hline 33 & Imazalil & 5 & 4.986 & $215 \rightarrow 173$ & 10 & $215 \rightarrow 145$ & 30 & Atrazine- $d_{5}$ \\
\hline 34 & Kresoxim-methyl & 5 & 5.019 & $116 \rightarrow 89$ & 20 & $206 \rightarrow 131$ & 20 & Atrazine- $d_{5}$ \\
\hline 35 & Lindane $(\gamma-\mathrm{BHC}$ or $\gamma-\mathrm{HCH})$ & 3 & 4.092 & $219 \rightarrow 183$ & 5 & $183 \rightarrow 147$ & 15 & Atrazine- $d_{5}$ \\
\hline 36 & Methamidophos & 1 & 2.855 & $141 \rightarrow 95$ & 5 & $95 \rightarrow 79$ & 10 & Atrazine- $d_{5}$ \\
\hline 37 & Methoxychlor & 7,8 & 5.507 & $227 \rightarrow 169$ & 30 & $227 \rightarrow 141$ & 30 & Atrazine- $d_{5}$ \\
\hline 38 & Mirex & 8 & 5.728 & $272 \rightarrow 237$ & 15 & $272 \rightarrow 143$ & 40 & Atrazine- $d_{5}$ \\
\hline 39 & Myclobutanil & 5 & 5.016 & $179 \rightarrow 125$ & 15 & $179 \rightarrow 90$ & 35 & Atrazine- $d_{5}$ \\
\hline 40 & cis-Nonachlor & 6 & 5.208 & $409 \rightarrow 300$ & 25 & $409 \rightarrow 145$ & 15 & Atrazine- $d_{5}$ \\
\hline 41 & trans-Nonachlor & 5 & 4.962 & $409 \rightarrow 300$ & 25 & $409 \rightarrow 145$ & 15 & Atrazine- $d_{5}$ \\
\hline 42 & Omethoate & 2 & 3.666 & $110 \rightarrow 79$ & 15 & $156 \rightarrow 110$ & 5 & Atrazine- $d_{5}$ \\
\hline 43 & Penconazole & 4 & 4.742 & $159 \rightarrow 89$ & 35 & $248 \rightarrow 157$ & 25 & Atrazine- $d_{5}$ \\
\hline 44 & Pentachlorothioanisole & 3 & 3.996 & $280 \rightarrow 237$ & 20 & $280 \rightarrow 265$ & 10 & Atrazine- $d_{5}$ \\
\hline 45 & Permethrin $(c i s+\text { trans })^{\mathrm{a}}$ & 8,9 & 5.835 & $183 \rightarrow 168$ & 15 & $183 \rightarrow 153$ & 15 & Atrazine- $d_{5}$ \\
\hline 46 & $o$-Phenylphenol & 2 & 3.485 & $170 \rightarrow 115$ & 35 & $170 \rightarrow 141$ & 20 & Atrazine- $d_{5}$ \\
\hline 47 & Piperonyl butoxide & 6,7 & 5.357 & $176 \rightarrow 103$ & 25 & $176 \rightarrow 131$ & 10 & Atrazine- $d_{5}$ \\
\hline
\end{tabular}


Table 1 continued

\begin{tabular}{|c|c|c|c|c|c|c|c|c|}
\hline Nos. & Analyte & $\begin{array}{l}\text { MS/MS } \\
\text { segment }\end{array}$ & $t_{\mathrm{R}}(\min )$ & $\begin{array}{l}\text { Quantifier } \\
\text { ion }(m / z)\end{array}$ & $\mathrm{CE}(\mathrm{V})$ & $\begin{array}{l}\text { Qualifier } \\
\text { ion }(\mathrm{m} / \mathrm{z})\end{array}$ & $\mathrm{CE}(\mathrm{V})$ & $\begin{array}{l}\text { Internal } \\
\text { standard (IS) }\end{array}$ \\
\hline 48 & Propargite & 6,7 & 5.353 & $135 \rightarrow 107$ & 10 & $135 \rightarrow 95$ & 10 & Atrazine- $d_{5}$ \\
\hline 49 & Pyridaben & 8,9 & 5.865 & $147 \rightarrow 117$ & 20 & $147 \rightarrow 91$ & 40 & Atrazine- $d_{5}$ \\
\hline 50 & Pyriproxyfen & 8 & 5.634 & $136 \rightarrow 78$ & 30 & $136 \rightarrow 96$ & 10 & Atrazine- $d_{5}$ \\
\hline 51 & Tebuconazole & 6,7 & 5.357 & $251 \rightarrow 125$ & 20 & $251 \rightarrow 127$ & 25 & Atrazine- $d_{5}$ \\
\hline 52 & Tetraconazole & 4 & 4.599 & $336 \rightarrow 218$ & 15 & $336 \rightarrow 156$ & 30 & Atrazine- $d_{5}$ \\
\hline 53 & Thiabendazole & 4 & 4.939 & $201 \rightarrow 174$ & 15 & $174 \rightarrow 65$ & 30 & Atrazine- $d_{5}$ \\
\hline 54 & Tribufos & 5 & 4.982 & $169 \rightarrow 113$ & 10 & $169 \rightarrow 95$ & 30 & Atrazine- $d_{5}$ \\
\hline \multicolumn{9}{|c|}{ Flame retardants (FRs) } \\
\hline 1 & BDE 183 & 10 & 7.205 & $720 \rightarrow 562$ & 20 & $720 \rightarrow 560$ & 20 & FBDE 126 \\
\hline 2 & Dechlorane plus (syn and anti) ${ }^{\mathrm{a}}$ & 11 & 8.300 & $272 \rightarrow 237$ & 20 & $272 \rightarrow 235$ & 20 & FBDE 126 \\
\hline 3 & PBB 153 & 9 & 6.315 & $468 \rightarrow 308$ & 40 & $468 \rightarrow 310$ & 30 & FBDE 126 \\
\hline 4 & $\begin{array}{l}\text { Pentabromoethylbenzene } \\
\text { (PBEB) }\end{array}$ & 6,7 & 5.289 & $500 \rightarrow 406$ & 40 & $500 \rightarrow 261$ & 40 & Atrazine- $d_{5}$ \\
\hline 5 & Pentabromotoluene (PBT) & 6 & 5.210 & $486 \rightarrow 407$ & 30 & $486 \rightarrow 326$ & 30 & FBDE 126 \\
\hline 6 & $\begin{array}{l}\text { 2-Ethylhexyl-2,3,4,5-tetrabro- } \\
\text { mobenzoate (TBB) }\end{array}$ & 8,9 & 5.994 & $421 \rightarrow 393$ & 10 & $421 \rightarrow 314$ & 20 & FBDE 126 \\
\hline 7 & $\begin{array}{l}\text { 1,2,5,6-Tetrabromocyclooctane } \\
\text { (TBCO) }\end{array}$ & 4,5 & 4.901 & $267 \rightarrow 105$ & 30 & $267 \rightarrow 91$ & 30 & Atrazine- $d_{5}$ \\
\hline 8 & $\begin{array}{l}\text { 1,2-Dibromo-4-(1,2-dibromoe- } \\
\text { thyl) cyclohexane }(\mathrm{TBECH})\end{array}$ & 4 & 4.702 & $267 \rightarrow 79$ & 40 & $267 \rightarrow 105$ & 40 & Atrazine- $d_{5}$ \\
\hline 9 & $\begin{array}{l}\text { Tribromoneopentyl alcohol } \\
\text { (TBNPA) }\end{array}$ & 2 & 3.665 & $214 \rightarrow 133$ & 10 & $214 \rightarrow 135$ & 10 & Atrazine- $d_{5}$ \\
\hline 10 & $\begin{array}{l}\text { 1,2,4,5-Tetrabromo-3,6-dimeth- } \\
\text { ylbenzene (TBX) }\end{array}$ & 4 & 4.809 & $422 \rightarrow 102$ & 40 & $422 \rightarrow 182$ & 40 & Atrazine- $d_{5}$ \\
\hline 11 & $\begin{array}{l}\text { tris(2-chloroethyl)phosphate } \\
\text { (TCEP) }\end{array}$ & 3 & 4.015 & $249 \rightarrow 63$ & 20 & $249 \rightarrow 99$ & 20 & Atrazine- $d_{5}$ \\
\hline 12 & $\begin{array}{l}\text { tris(1-chloro-2-propyl)phos- } \\
\text { phate (TCPP) }\end{array}$ & 3 & 4.127 & $277 \rightarrow 125$ & 20 & $277 \rightarrow 99$ & 20 & Atrazine- $d_{5}$ \\
\hline 13 & $\begin{array}{l}\text { tris(1,3-dichloro-2-propyl) } \\
\text { phosphate (TDCPP) }\end{array}$ & 6,7 & 5.248 & $381 \rightarrow 159$ & 20 & $381 \rightarrow 79$ & 20 & Atrazine- $d_{5}$ \\
\hline 14 & Triphenyl phosphate (TPP) & 6,7 & 5.380 & $326 \rightarrow 169$ & 30 & $326 \rightarrow 77$ & 30 & Atrazine- $d_{5}$ \\
\hline \multicolumn{9}{|c|}{$\begin{array}{l}\text { Polycyclic aromatic } \\
\text { hydrocarbons (PAHs) }\end{array}$} \\
\hline 1 & Acenaphthene & 2 & 3.465 & $153 \rightarrow 152$ & 30 & $153 \rightarrow 151$ & 30 & $\begin{array}{l}\text { Acenaphthalene- } \\
d_{8}\end{array}$ \\
\hline 2 & Acenaphthylene & 2 & 3.380 & $152 \rightarrow 151$ & 30 & $152 \rightarrow 126$ & 20 & $\begin{array}{l}\text { Acenaphthyl- } \\
\text { ene- } d_{8}\end{array}$ \\
\hline 3 & Anthracene & 4 & 4.183 & $178 \rightarrow 176$ & 40 & $178 \rightarrow 152$ & 40 & $\begin{array}{l}\text { Phenanthrene- } \\
d_{10}\end{array}$ \\
\hline 4 & Benz(a)anthracene + chrysene & 7,8 & 5.563 & $228 \rightarrow 226$ & 25 & $228 \rightarrow 227$ & 25 & Pyrene- $d_{10}$ \\
\hline 5 & Benzo(a)pyrene & 9 & 6.231 & $252 \rightarrow 250$ & 40 & $252 \rightarrow 226$ & 40 & $\begin{array}{l}\text { Benzo(a)pyrene- } \\
d_{12}\end{array}$ \\
\hline 6 & Benzo $(b+k) f l u o r a n t h e n e$ & 8 & 6.064 & $252 \rightarrow 250$ & 40 & $252 \rightarrow 226$ & 40 & $\begin{array}{l}\text { Benzo(a)pyrene- } \\
d_{12}\end{array}$ \\
\hline 7 & Benzo(g,h,i)perylene & 10 & 7.115 & $276 \rightarrow 274$ & 40 & $276 \rightarrow 275$ & 40 & $\begin{array}{l}\operatorname{Benzo}(\mathrm{g}, \mathrm{h}, \mathrm{i}) \\
\text { perylene- } d_{12}\end{array}$ \\
\hline 8 & Dibenz $(\mathrm{a}, \mathrm{h})$ anthracene & 10 & 6.985 & $278 \rightarrow 252$ & 40 & $278 \rightarrow 250$ & 40 & $\begin{array}{l}\text { Benzo(a)pyrene- } \\
d_{12}\end{array}$ \\
\hline 9 & Fluoranthene & 4 & 4.809 & $202 \rightarrow 200$ & 40 & $202 \rightarrow 201$ & 40 & Fluoranthene- $d_{10}$ \\
\hline 10 & Fluorene & 2 & 3.675 & $165 \rightarrow 164$ & 30 & $165 \rightarrow 163$ & 30 & $\begin{array}{l}\text { Phenanthrene- } \\
\text { d10 }\end{array}$ \\
\hline
\end{tabular}


Table 1 continued

\begin{tabular}{|c|c|c|c|c|c|c|c|c|}
\hline Nos. & Analyte & $\begin{array}{l}\text { MS/MS } \\
\text { segment }\end{array}$ & $t_{\mathrm{R}}(\min )$ & $\begin{array}{l}\text { Quantifier } \\
\text { ion }(m / z)\end{array}$ & $\mathrm{CE}(\mathrm{V})$ & $\begin{array}{l}\text { Qualifier } \\
\text { ion }(m / z)\end{array}$ & $\mathrm{CE}(\mathrm{V})$ & $\begin{array}{l}\text { Internal } \\
\text { standard (IS) }\end{array}$ \\
\hline 11 & Indeno(1,2,3-c,d)pyrene & 10 & 6.926 & $276 \rightarrow 274$ & 30 & $276 \rightarrow 275$ & 30 & $\begin{array}{l}\operatorname{Benzo}(\mathrm{g}, \mathrm{h}, \mathrm{i}) \\
\text { perylene- } d_{12}\end{array}$ \\
\hline 12 & Naphthalene & 1 & 2.775 & $128 \rightarrow 102$ & 20 & $128 \rightarrow 127$ & 20 & Naphthalene- $d_{8}$ \\
\hline 13 & Phenanthrene & 3 & 4.160 & $178 \rightarrow 176$ & 40 & $178 \rightarrow 152$ & 40 & $\begin{array}{l}\text { Phenanthrene- } \\
d_{10}\end{array}$ \\
\hline 14 & Pyrene & 5 & 4.943 & $202 \rightarrow 200$ & 40 & $202 \rightarrow 201$ & 40 & Pyrene- $d_{10}$ \\
\hline \multicolumn{9}{|c|}{$\begin{array}{l}\text { Polychlorinated } \\
\text { biphenyls (PCBs) }\end{array}$} \\
\hline 1 & PCB 77 & 6 & 5.049 & $292 \rightarrow 222$ & 40 & $292 \rightarrow 220$ & 25 & ${ }^{13} \mathrm{C}_{12}$-PCB 153 \\
\hline 2 & PCB 81 & 5 & 5.010 & $292 \rightarrow 222$ & 40 & $292 \rightarrow 220$ & 25 & ${ }^{13} \mathrm{C}_{12}$-PCB 153 \\
\hline 3 & PCB 105 & 7 & 5.251 & $326 \rightarrow 256$ & 30 & $326 \rightarrow 254$ & 30 & ${ }^{13} \mathrm{C}_{12}$-PCB 153 \\
\hline 4 & PCB 114 & 6 & 5.193 & $326 \rightarrow 256$ & 30 & $326 \rightarrow 254$ & 30 & ${ }^{13} \mathrm{C}_{12}$-PCB 153 \\
\hline 5 & PCB $118+123$ & 5 & 5.144 & $326 \rightarrow 254$ & 30 & $326 \rightarrow 256$ & 30 & ${ }^{13} \mathrm{C}_{12}$-PCB 153 \\
\hline 6 & PCB 126 & 7 & 5.366 & $326 \rightarrow 256$ & 40 & $326 \rightarrow 254$ & 40 & ${ }^{13} \mathrm{C}_{12}$-PCB 153 \\
\hline 7 & PCB $156+157$ & 7 & 5.538 & $360 \rightarrow 288$ & 40 & $360 \rightarrow 290$ & 40 & ${ }^{13} \mathrm{C}_{12}$-PCB 153 \\
\hline 8 & PCB 167 & 8 & 5.421 & $360 \rightarrow 290$ & 40 & $360 \rightarrow 288$ & 40 & ${ }^{13} \mathrm{C}_{12}$-PCB 153 \\
\hline 9 & PCB 169 & 8 & 5.650 & $360 \rightarrow 288$ & 40 & $360 \rightarrow 290$ & 40 & ${ }^{13} \mathrm{C}_{12}$-PCB 153 \\
\hline 10 & PCB 170 & 7,8 & 5.695 & $394 \rightarrow 324$ & 40 & $394 \rightarrow 322$ & 40 & ${ }^{13} \mathrm{C}_{12}$-PCB 153 \\
\hline 11 & PCB 180 & 8 & 5.575 & $394 \rightarrow 324$ & 40 & $394 \rightarrow 322$ & 40 & ${ }^{13} \mathrm{C}_{12}$-PCB 153 \\
\hline 12 & РCВ 189 & 9 & 5.786 & $394 \rightarrow 324$ & 40 & $394 \rightarrow 322$ & 40 & ${ }^{13} \mathrm{C}_{12}$-PCB 153 \\
\hline \multicolumn{9}{|c|}{$\begin{array}{l}\text { Internal standards (IS) } \\
\text { and quality control } \\
\text { (QC) standard }\end{array}$} \\
\hline 1 & ${ }^{13} \mathrm{C}_{12}$-PCB 153 (IS) & 6 & 5.185 & $372 \rightarrow 302$ & 40 & & & \\
\hline 2 & Acenaphthalene- $d_{8}$ (IS) & 2 & 3.339 & $160 \rightarrow 158$ & 30 & & & \\
\hline 3 & Atrazine- $d_{5}($ IS $)$ & 3 & 3.956 & $205 \rightarrow 105$ & 15 & & & \\
\hline 4 & Benzo(a)pyrene- $d_{12}$ (IS) & 8,9 & 6.261 & $264 \rightarrow 260$ & 40 & & & \\
\hline 5 & Benzo $(\mathrm{g}, \mathrm{h}, \mathrm{i})$ perylene- $d_{12}$ (IS) & 10 & 7.122 & $288 \rightarrow 284$ & 40 & & & \\
\hline 6 & FBDE 126 (IS) & 9 & 6.223 & $582 \rightarrow 315$ & 40 & & & \\
\hline 7 & Fenthion- $d_{6}$ (IS) & 4 & 4.500 & $284 \rightarrow 115$ & 20 & & & \\
\hline 8 & Fluoranthene- $d_{10}$ (IS) & 4 & 4.89 & $212 \rightarrow 208$ & 40 & & & \\
\hline 9 & Naphthalene- $d_{8}$ (IS) & 1 & 2.744 & $136 \rightarrow 80$ & 40 & & & \\
\hline 10 & Phenanthrene- $d_{10}$ (IS) & 3 & 4.11 & $188 \rightarrow 160$ & 20 & & & \\
\hline 11 & Pyrene- $d_{10}($ IS $)$ & 5 & 4.89 & $212 \rightarrow 210$ & 40 & & & \\
\hline 12 & $p$-Terphenyl- $d_{14}(\mathrm{QC})$ & 5 & 4.985 & $244 \rightarrow 212$ & 40 & & & \\
\hline
\end{tabular}

All ion transitions used wide resolution setting and $4 \mathrm{~ms}$ dwell times. Segment start times were: $1=2.35$ min; $2=3.1 ; 3=3.9 ; 4=4.35$; $5=4.9 ; 6=5.15 ; 7=5.35 ; 8=5.5 ; 9=6 ; 10=6.75 ;$ and $11=8$; end 9 min

${ }^{\text {a }}$ Multiple peaks

containing $1.1 \%$ formic acid to enhance pesticide stability of final extract [20]. As a post-cleanup quality control (QC) standard, $p$-terphenyl- $d_{14}$ (from AccuStandard) was included in the APs mixture at $0.88 \mathrm{ng} \mu \mathrm{L}^{-1}$.

Eleven different food matrices including Gala apple, kiwi, kale, carrot, navel orange, canned black olives, wheat grain, dried basil, pork loin, salmon, and avocado were purchased from local grocery stores. The samples were comminuted with dry ice using a Robot Coupe (Ridgeway, MS;
USA) RSI $2 \mathrm{Y} 1$ chopper and stored in glass jars at $-20{ }^{\circ} \mathrm{C}$ until analysis.

\section{Sample Extraction}

Comminuted samples of apple, kiwi, carrot, kale, orange, black olive, pork loin, salmon, and avocado $(15 \mathrm{~g})$ were individually weighed in $50 \mathrm{~mL}$ polypropylene tubes along with $7.5 \mathrm{~g} \mathrm{HCO}_{2} \mathrm{NH}_{4}$, which was extracted for $10 \mathrm{~min}$ with 
Table 2 Steps and time for the 8 min automated mini-SPE method

\begin{tabular}{llr}
\hline Step & Description & Time (s) \\
\hline 1 & Wash the $1 \mathrm{~mL}$ syringe with MeCN (2 pumps of $0.5 \mathrm{~mL}$ each) & 30 \\
2 & Load $300 \mu \mathrm{L}$ extract from AS vial in Tray1 into $1 \mathrm{~mL}$ syringe & 10 \\
3 & Place mini-cartridge above collection AS vial (with glass insert) in Tray2 & 10 \\
4 & Elute extract through mini-cartridge at $2 \mu \mathrm{L} \mathrm{s}{ }^{-1}$ & 150 \\
5 & Discard mini-cartridge into waste receptacle & 5 \\
6 & Wash the $1 \mathrm{~mL}$ syringe with $1 / 1 / 1 \mathrm{MeCN} / \mathrm{MeOH} /$ water $(2$ pumps of $0.5 \mathrm{~mL}$ each) & 30 \\
7 & Wash the $1 \mathrm{~mL}$ syringe with MeCN (4 pumps of $0.5 \mathrm{~mL}$ each) & 45 \\
8 & Switch to $100 \mu \mathrm{L}$ syringe and wash with MeCN (2 pumps of $50 \mu \mathrm{L}$ each) & 50 \\
9 & Add $25 \mu \mathrm{L} \mathrm{MeCN}$ to collection AS vial (with glass insert) in Tray2 & 10 \\
10 & Add $25 \mu \mathrm{LP}+$ QC sol'n to collection AS vial (with glass insert) in Tray2 & 10 \\
11 & Wash the $100 \mu \mathrm{L}$ syringe with $1 / 1 / 1 \mathrm{MeCN} / \mathrm{MeOH} /$ water $(5$ pumps of $50 \mu \mathrm{L}$ each) & 50 \\
12 & Wash the $100 \mu \mathrm{L}$ syringe with MeCN (3 pumps of $50 \mu \mathrm{L}$ each) & 40 \\
13 & Switch to $1 \mathrm{~mL}$ syringe and move to home position & 40 \\
\hline
\end{tabular}

The cleanup itself only took $\approx 3 \mathrm{~min}$, and syringe wash and exchange steps took $\approx 5 \mathrm{~min}$
$15 \mathrm{~mL}$ MeCN using a Glas-Col (Terre Haute, IN; USA) platform pulse mixer at $80 \%$ setting with maximum pulsation. For wheat grain and dried basil, $5 \mathrm{~g}$ sample $+15 \mathrm{~mL}$ water $+7.5 \mathrm{~g} \mathrm{HCO}_{2} \mathrm{NH}_{4}$ was added to the tubes with $15 \mathrm{~mL} \mathrm{MeCN}$ and extraction time was $60 \mathrm{~min}$ using the platform shaker (capacity of 50 tubes at a time). For reagent blanks, $15 \mathrm{~mL}$ water represented the sample. Then, centrifugation at $4150 \mathrm{rpm}$ ( $3711 \mathrm{rcf})$ at room temperature for 3 min was conducted using a Thermo Fisher (Waltham, MA; USA) Sorvall Legend RT centrifuge (capacity of twenty $50 \mathrm{~mL}$ tubes at a time). Extracts of individual matrices were combined and spiked (or not) with the analytes and IS to evaluate the automated mini-SPE cleanup step. The initial extracts (spiked or not) were transferred to $1.8 \mathrm{~mL}$ standard ambler glass autosampler (AS) vials, which were closed with split septa caps.

\section{Automated Mini-SPE Cleanup}

As previously described [12], two different types of SPE mini-cartridges were purchased for evaluation from ITSP solutions (Hartwell, GA; USA): (1) $45 \mathrm{mg}$ anh. $\mathrm{MgSO}_{4} /$ primary secondary amine (PSA) $/ \mathrm{C}_{18} /$ CarbonX (in the ratio of 20/12/12/1, w/w/w/w, respectively); and (2) $30 \mathrm{mg} \mathrm{C}_{18} / \mathrm{Z}$ Sep/CarbonX (20.7/8.3/1, w/w/w, respectively). The minicartridges, as shown in the Table of Contents graphic and Supplemental information, were $3.5 \mathrm{~cm}$ long with a $0.8 \mathrm{~cm}$ diameter.

Automated mini-SPE was conducted using a Gerstel (Linthicum, MD; USA) robotic MultiPurpose Sampler (MPS) liquid handling system [also known as a PAL3-RTC from CTC Analytics (Zwingen, Switzerland)]. PAL Sample Control (CTC Analytics) software was used to program and operate the device. The steps in the final automated miniSPE cleanup method using the $45 \mathrm{mg}$ 4-sorbent mixture
(\#1 above) are shown in Table 2. For matrix-matched calibration standards, Step 9 to add $25 \mu \mathrm{L} \mathrm{MeCN}$ was not done (Step 10 to add the APs + QC solution was still done), and instead, $25 \mu \mathrm{L}$ of the appropriate calibration standard solutions were added manually to the matrix blank extracts.

Procedurally, the AS vials containing the initial extracts were placed into a 54 position tray (Tray1), and the corresponding collection AS vials with glass micro-inserts (300 $\mu \mathrm{L})$ and split septa caps were placed into a second 54 position tray (Tray2). An ITSP vial guide cover for the minicartridges was placed atop the vials in Tray2. A third tray (Tray3) contained 96 mini-cartridges placed above a solvent waste drain (if pre-conditioning with solvent is desired). The same tray holder contained all 3 trays, and our system was fitted with two tray holders for a potential capacity of 108 samples for sequential unattended automated cleanup.

The robotic liquid handler was fitted with 3 interchangeable glass syringes (gastight with $57 \mathrm{~mm}$ long, 22 gage, straight tip needles) in different slots: 10,1 , and $0.1 \mathrm{~mL}$. As shown in Table 2, only the 1 and $0.1 \mathrm{~mL}$ syringes were used in the experiments, and if we had chosen to install the device onto the LPGC-MS/MS instrument as designed as an option by the manufacturers, we would have chosen to replace the $10 \mathrm{~mL}$ syringe with a $5-10 \mu \mathrm{L}$ syringe for direct injection of final extracts after cleanup. Instead, we chose to use the device in stand-alone fashion at this time (greater flexibility in independent operations for both LC and GC analyses).

The collection vials were pre-weighed to the nearest $\mathrm{mg}$ prior to and after conducting mini-SPE, and weight differences were recorded to assess consistency of the liquid transfers and final extract volumes. After weighing and preparation of calibration standards, the vials were recapped with non-slit septa, vortexed $\approx 1 \mathrm{~s}$ to mix, and placed on the autosampler tray for LPGC-MS/MS analysis. 
Equivalent sample concentrations of final extracts dehydrated by anh. $\mathrm{MgSO}_{4}$ in mini-SPE were $1 \mathrm{~g} \mathrm{~mL}^{-1}$ for fruits and vegetables, and $0.33 \mathrm{~g} \mathrm{~mL}^{-1}$ for wheat grain and dried basil.

\section{Fast LPGC-MS/MS Analysis}

Table 1 lists the 97 targeted analytes (three analyzed together) plus 12 internal and quality control standards and their conditions in LPGC-MS/MS analysis. An Agilent (Little Falls, DE; USA) 7890A/7010 gas chromatograph/ triple quadrupole mass spectrometer was employed using electron ionization (EI) at $-70 \mathrm{eV}$ and $100 \mu \mathrm{A}$ filament current. The separation was achieved on a $15 \mathrm{~m} \times 0.53 \mathrm{~mm}$ i.d. $\times 1 \mu \mathrm{m}$ film thickness Phenomenex (Torrance, CA; USA) ZB-5MSi analytical column connected using an Agilent Ultimate union to a $5 \mathrm{~m} \times 0.18 \mathrm{~mm}$, i.e., uncoated restrictor/guard column from Restek (Bellefonte, PA, USA). The calculated virtual column length was $5.5 \mathrm{~m} \times 0.18 \mathrm{~mm}$, i.e., and constant flow rate of $\mathrm{He}$ $(99.999 \%)$ carrier gas was $2 \mathrm{~mL} \mathrm{~min}^{-1}$. Details about the theory and practice of LPGC-MS/MS have been reported previously [17].

The GC oven temperature program was $70{ }^{\circ} \mathrm{C}$ for $1.5 \mathrm{~min}$, ramped at $80-180{ }^{\circ} \mathrm{C} \mathrm{min}^{-1}$, then 40-250 ${ }^{\circ} \mathrm{C} \min ^{-1}$, followed by $70-320{ }^{\circ} \mathrm{C} \min ^{-1}$, held for $4.4 \mathrm{~min}$ (10.025 min total). Cool down and re-equilibration time was $3 \mathrm{~min}$. The transfer line temperature was $280^{\circ} \mathrm{C}$, ion source was $320^{\circ} \mathrm{C}$, and quadrupoles were kept at $150^{\circ} \mathrm{C}$. Collision gas flow rate was $1.5 \mathrm{~mL} \mathrm{~min}^{-1} \mathrm{~N}_{2}$ and quench gas was $2.25 \mathrm{~mL} \mathrm{~min}^{-1} \mathrm{He}$. The Agilent multimode inlet conditions were the same as reported previously [10, 18], except injection volume was reduced to $1.0 \mu \mathrm{L}$ plugged between $1.5 \mu \mathrm{L}$ air above and below in the syringe. An Agilent Ultra-inert $2 \mathrm{~mm}$ dimpled splitless liner was placed in the inlet and Agilent Mass Hunter version B07 software was used for instrument control and data processing.

When using APs, extensive post-injection washing of the syringe with aqueous solution is very important to avoid sticking of the plunger if the sugar derivatives precipitate onto surfaces. In this study, the wash steps of the $10 \mu \mathrm{L}$ syringe entailed $10 \times 5 \mu \mathrm{L}$ of $1 / 1 / 1(\mathrm{v} / \mathrm{v} / \mathrm{v}) \mathrm{MeCN} /$ $\mathrm{MeOH} /$ water followed by $10 \times 5 \mu \mathrm{L}$ of $\mathrm{MeCN}$ after every injection. The pre-injection wash steps called for another 5 $\mu \mathrm{L}$ of the aqueous wash solution and $2 \times 5 \mu \mathrm{L}$ of $\mathrm{MeCN}$, each contained in $100 \mathrm{~mL}$ wash bottles.

\section{Method Optimization and Validation Experiments}

To evaluate the consistency and performance of the automated mini-SPE application, and to assess cleanup efficiency and analyte retention vs. elution volumes for the two different cartridges, the 97 analytes were spiked into extracts of four different matrices (kale, avocado, pork, and salmon). Spiking level was $100 \mathrm{ng} \mathrm{mL}^{-1}\left(10 \mathrm{ng} \mathrm{mL}^{-1}\right.$ for PCBs), and five different volumes $(200,300,400,500$, and $600 \mu \mathrm{L}$ ) of extracts in triplicate were loaded into the cartridges at $2 \mu \mathrm{L} \mathrm{s}^{-1}$. Proportional amounts of AP + QC mix were added to the final extracts depending on elution volumes, and the cleanup efficiency was compared in full scan LPGC-MS and UV-Vis measurements. A Synergy HT Multi-detection microplate reader from Bio-Tek (Winooski, VT; USA) was used for optical density measurements. Relative recoveries of the analytes vs. extract load/elution volumes were measured using LPGC-MS/MS.

The final mini-SPE cleanup method was validated by spiking QuEChERS extracts of 10 sample matrices (Gala apple, kiwi, kale, carrot, navel orange, canned black olive, wheat grain, dried basil, pork loin, and salmon) at 10, 25, 50 , and $100 \mathrm{ng} \mathrm{mL}^{-1}$ (ten times lower for PCBs) with $n=4$ at each level and matrix. A pair of chemists prepared and analyzed 47 samples (65 injections) of two matrices per day (LPGC-MS/MS sequences took $\approx 14 \mathrm{~h}$ ). The recoveries and RSDs were determined from peak areas generated from summation function integration normalized (or not, for comparison purposes) to the corresponding IS listed in Table 1 for each analyte. Matrix-matched (MM) and reagent-only (RO) calibration standards (7 levels each: 0, 5, $10,25,50,100$, and $150 \mathrm{ng} \mathrm{mL}^{-1}$; tenfold lower for PCBs) were prepared by adding $25 \mu \mathrm{L}$ calibration standards to final matrix blank extracts (MM) or $220 \mu \mathrm{L} \mathrm{MeCN}+25$ $\mu \mathrm{L} \mathrm{AP}+\mathrm{QC}$ solution (RO). The calibration solutions in $\mathrm{MeCN}$ each contained $0.88 \mathrm{ng} \mu \mathrm{L}^{-1}$ IS and $0,0.044,0.088$,

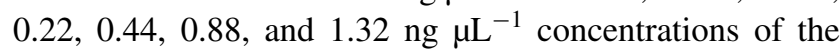
analytes (tenfold lower for PCBs and ${ }^{13} \mathrm{C}_{12}$ - $\mathrm{PCB} 153$ as the IS) to yield the seven levels listed above. Matrix effects (MEs) were calculated as the \% difference in least-linear squared calibration slopes of the MM vs. RO calibration standards.

\section{Results and Discussion}

\section{LPGC-MS/MS Analysis}

In previous LPGC-MS/MS studies in our group, we used a 7000A MS/MS instrument [10, 21], which was upgraded to a $7000 \mathrm{~B}[13,18]$, and now to a 7010 system. In regulatory monitoring of pesticide residues in foods, the need of analysis calls for LOQ $<10 \mathrm{ng} \mathrm{g}^{-1}$ [22]. The injection of the least amount of sample equivalent to meet the desired LOQ improves the ruggedness of the method and reduces instrument maintenance demands. Originally with the 7000A instrument, $10 \mathrm{mg}$ sample equivalent $\left(1 \mathrm{mg} \mu \mathrm{L}^{-1}\right.$ QuEChERS extracts in $\mathrm{MeCN}$ ) was injected [10, 21], which was reduced to $2.5 \mathrm{mg}$ when using the $7000 \mathrm{~B}$ [18]. In this 
study, the 7010 upgrade enabled injection of $1 \mathrm{mg}(1 \mu \mathrm{L})$ sample equivalent to still achieve $<5 \mathrm{ng} \mathrm{g}^{-1}$ LOQs for all analytes in the fruit and vegetable matrices. Cold inlet conditions using programmable temperature vaporization were used in each method thus far, but in the near future, we plan to investigate hot split mode injections to further speed the analysis, possibly improve performance, and reduce the amount of matrix components being introduced into the instrument [23].

We started to estimate LOQs from the final method in this study, but recognized quickly that the calculations were inaccurate due to ultra-trace carry over or artifacts that infiltrated the background for nearly all analytes in $\mathrm{MeCN}$, reagent, and matrix blanks. The carry over averaged $0.4 \%$ of the previous injection, and likely originated from the injection syringe needle contaminating the $100 \mathrm{~mL}$ wash bottles on the autosampler, not from the mini-SPE procedure which prepared 14 blank extracts prior to the reagent blank in its sequence.

Peak integration was conducted using the summation function in the Agilent MassHunter software, which simply drew a baseline at the lowest point between analyst-defined start and stop times to cover the $t_{\mathrm{R}}$ and peak width for each analyte. The integration start and stop times were set by ensuring that they fully covered the analyte peaks for all 325 injections over the course of all five sequences in the validation study. The peak area was always positive using this software's summation integration function, which led to positive responses even when only noise was present. However, inspection of the MRM chromatograms and ion ratios clearly indicated that the background peaks in reagent and solvent blanks originated from the analytes in most cases, not simply electronic or chemical noise. The equivalent background concentrations of analytes in RO blanks averaged $0.5 \mathrm{ng} \mathrm{mL}^{-1}$ for the pesticides, FRs, and PAHs, and $0.05 \mathrm{ng} \mathrm{mL}^{-1}$ for PCBs, which did not affect the results of the study, but also did not permit an accurate estimation of LOQs. The likely source of carryover can be eliminated using a newer type of flowing solvent wash station that rinses the analytes coating the needle to waste rather than allowing them to contaminate the fixed volume wash solutions. LOQs can be better estimated after this issue is resolved, but the $1 \mu \mathrm{L}$ injection clearly met analytical purposes in this application. We can conclude that the LPGC-MS/MS method yielded LOQs $<0.5 \mathrm{ng} \mathrm{g}^{-1}$ $\left(<0.05 \mathrm{ng} \mathrm{g}^{-1}\right.$ for PCBs) for all but a few analytes, such as fenpropathrin, endosulfans, and BDE 183 which gave LOQs $\approx 1 \mathrm{ng} \mathrm{g}^{-1}$.

\section{Automated Mini-SPE}

Morris and Schriner [12] reported that mini-SPE cartridges containing $20 \mathrm{mg}$ anh. $\mathrm{MgSO}_{4}, 12 \mathrm{mg}$ PSA and $\mathrm{C}_{18}$ each, and $1 \mathrm{mg}$ CarbonX (45 mg total) provided satisfactory cleanup and recoveries for a wide range of pesticides and matrices in GC-MS/MS analysis. For LC-MS/MS, they chose to use cartridges containing $20.7 \mathrm{mg} \mathrm{C} 18,8.3 \mathrm{mg}$ Z-Sep, and $1 \mathrm{mg}$ CarbonX ( $30 \mathrm{mg}$ total), which provided acceptable cleanup and pesticide recoveries for monitoring purposes [12]. In their method, they pre-conditioned the mini-cartridge with $150 \mu \mathrm{L} \mathrm{MeCN}$, added $150 \mu \mathrm{L}$ QuEChERS extract, then eluted with another $150 \mu \mathrm{L}$ elution solvent.

In d-SPE of QuEChERS extracts, no pre-conditioning or extra solvent elution steps are done, and the $\mathrm{MeCN}$ extract itself serves as the elution solvent. Ideally, the sorbents only adsorb co-extracted matrix components and not analytes. We decided to streamline and speed the method of Morris and Schriner [12] by eliminating the $\mathrm{MeCN}$ pre-conditioning and solvent elution steps for the same mini-cartridges they developed, which are commercially available. They conducted very thorough studies to set the sorbent combinations, and we had previously found similar sorbent mixtures work well for cleanup and analysis pesticides and environmental contaminants in seafood matrices using filter-vial d-SPE [13]. We have since extended the filter-vial d-SPE method to other animal tissues (cattle, pork, and chicken muscle), but found that only filtering of initial extracts was needed for analysis of the $99 \mathrm{LC}$-amenable pesticides in our recent approach [18].

In this evaluation, we focused on 97 representative GCamenable analytes and compared the two different minicartridges for their analysis in QuEChERS extracts of kale, salmon, pork, and avocado, and using extract load volumes of $200,300,400,500$, and $600 \mu \mathrm{L}$. To determine elution and dead volumes of the mini-cartridges, weights of the collection vials were compared before and after cleanup. Figure 1 shows the results in which measured dead volume (based on measured solution densities) was found to increase slightly as more extract was loaded into the mini-cartridges at $2 \mu \mathrm{L} \mathrm{s}{ }^{-1}$. The reason for this observance was very likely because more interstitial spaces in the sorbent beds were being filled as more solution was passed through the cartridges. In any case, the dead volumes were much the same for both types of mini-cartridges, and averaged $75 \pm 5$ to $90 \pm 8 \mu \mathrm{L}$ from 200 to $600 \mu \mathrm{L}$ extract load volumes, respectively. Thus, the measured extract elution volumes were $125 \pm 5$ to $510 \pm 8 \mu \mathrm{L}$ from 200 to $600 \mu \mathrm{L}$ extract load volumes, respectively, which provided known and rather consistent elution volumes in the method.

In the validation study involving 235 mini-SPE cartridges, final extracts averaged $278 \pm 5 \mu \mathrm{L}(1.9 \% \mathrm{RSD})$, in which only 4 final extracts had $\approx 25 \mu \mathrm{L}$ reduced volume. The robotic liquid handler operated flawlessly throughout the study, and perhaps vial weights were transcribed 


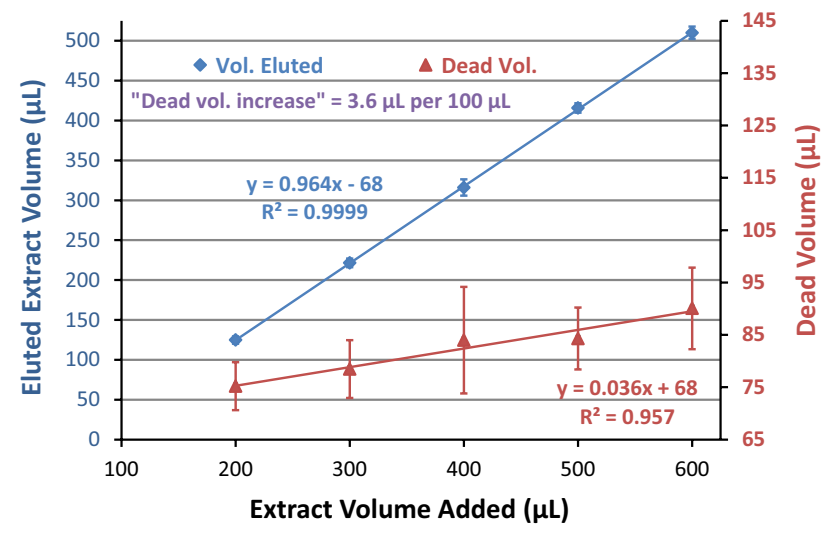

Fig. 1 Eluted extract and dead volumes of the mini-SPE cartridges in cleanup of QuEChERS extracts of kale, avocado, pork, and salmon ( $n=12$ for each extract load volume)

improperly, bubbles materialized in the syringe, or minicartridge dead volumes were larger, which caused those four outliers.

\section{Mini-SPE Cleanup}

Full scan LPGC-MS chromatograms of the reagent blank, kale, avocado, salmon, and pork QuEChERS extracts were compared before and after the mini-SPE cleanup using the $200-600 \mu \mathrm{L}$ load volumes. Results indicated that the $30 \mathrm{mg}$ $\mathrm{C}_{18} / \mathrm{Z}$-Sep/CarbonX (20.7/8.3/1, w/w/w) mini-cartridges provided little cleanup for any of the 4 matrices independent of extract load/elution volumes (see Supplemental information). The chromatograms appeared much the same in each injection. These mini-cartridges were devised for LC-MS/MS [12], and this LPGC-MS result is probably due to the lack of anh. $\mathrm{MgSO}_{4}$ in the cartridges to reduce water content in the final extracts. Density measurements of final extracts indicated that the $45 \mathrm{mg}$ mini-cartridges containing $20 \mathrm{mg}$ anh. $\mathrm{MgSO}_{4}$ led to cleaned extracts (before addi-

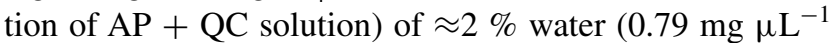
density of the $\mathrm{MeCN}$ extracts) and the $30 \mathrm{mg}$ cartridges without anh. $\mathrm{MgSO}_{4}$ maintained the same extract density $\left(0.82 \mathrm{mg} \mathrm{\mu L}^{-1}\right)$ as the initial extracts, which were $\approx 15 \%$ moisture. Drier solutions are better for GC analyses and provide stronger adsorption properties for common sorbents (e.g. PSA, Z-Sep, silica, Florisil, Alumina).

In the case of the $45 \mathrm{mg}$ mini-cartridges of 20/12/12/1 anh. $\mathrm{MgSO}_{4} / \mathrm{PSA} / \mathrm{C}_{18} /$ CarbonX, significant removal of matrix co-extractives was observed in the LPGC-MS chromatograms of kale, pork, and salmon, but little difference was observed for avocado (see Fig. 2). As would be expected, greater cleanup took place using smaller load/elution volumes before breakthrough began to occur. Depending on analyte recoveries, $200-300 \mu \mathrm{L}$ would be preferably chosen to provide more cleanup and shorter time than achieved with larger volumes.

Unlike LPGC-MS, UV-Vis absorbance spectrometry of the $200-600 \mu \mathrm{L}$ final extracts $(200 \mu \mathrm{L}$ of combined replicates in 96-well plates) showed similar cleanup efficiencies using either the 45 or $30 \mathrm{mg}$ mini-cartridges (see Supplemental information). As shown in Fig. 3, chlorophyll and xanthophyll co-extractives from the kale in particular were nearly eliminated by the sorbents, mainly due to CarbonX. Salmon and pork extracts were nearly colorless, and measured UV-Vis cleanup efficiency was small compared to full scan LPGC-MS results. In the case of avocado as shown in Fig. 2, LPGC-MS showed little differences in full scan chromatograms, but UV-Vis spectra exhibited strong reduction in absorbance readings from 300 to $700 \mathrm{~nm}$ (see Supplemental information). Kale co-extractives were dramatically reduced in both types of measurement; especially by the $45 \mathrm{mg}$ mini-cartridges (see Figs. 2, 3).

\section{Analyte Retention in Mini-SPE}

The extract elution volume not only affected the cleanup efficiency in mini-SPE, but analyte recoveries also depend on load/elution volume. LPGC-MS/MS was used to compare relative recoveries (w/o using IS) normalized to the average $600 \mu \mathrm{L}$ result with respect to extract load volumes in triplicate for each of the four matrices. Figure 4 shows an example of typical results that were representative of nearly all of the pesticides, demonstrating that neither load/ elution volume nor matrix made a significant difference in recoveries. The $30 \mathrm{mg} \mathrm{3}$-sorbent mixture mini-cartridges also gave similar analyte results as the $45 \mathrm{mg}$ 4-sorbent mini-cartridges. Figure 5 shows the results for the IS with respect to extract load volumes. Only PAHs and a few other analytes with co-planar chemical structures gave less than complete elution, mainly due to partial retention on CarbonX. Hexachlorobenzene (HCB) is one the few pesticides that gave incomplete elution at $200 \mu \mathrm{L}$ extract load volume. Figure 6 shows how $300 \mu \mathrm{L}$ load volume $(\approx 220$ $\mu \mathrm{L}$ elution) yielded $\approx 80 \%$ relative HCB recovery while still removing $\approx 95 \%$ of co-extracted chlorophyll from initial QuEChERS extracts of kale. PBDE 183 and co-planar PCBs (126 and 169) yielded similar results as HCB, but large PAHs ( $\geq 3$ rings) did not fully elute even with $>500$ $\mu \mathrm{L}$ load volumes. Similar results were achieved with the $30 \mathrm{mg}$ mini-cartridges, indicating that $1 \mathrm{mg}$ CarbonX was mostly responsible for the retention of the PAHs. As shown in Supplemental information, no significant differences were observed in the relative recoveries for the analytes when using either type of mini-cartridge. Independent of extract volumes, isotopically labeled IS of several PAHs were expected to help compensate for reduced actual recoveries in the final method (see Fig. 5). 

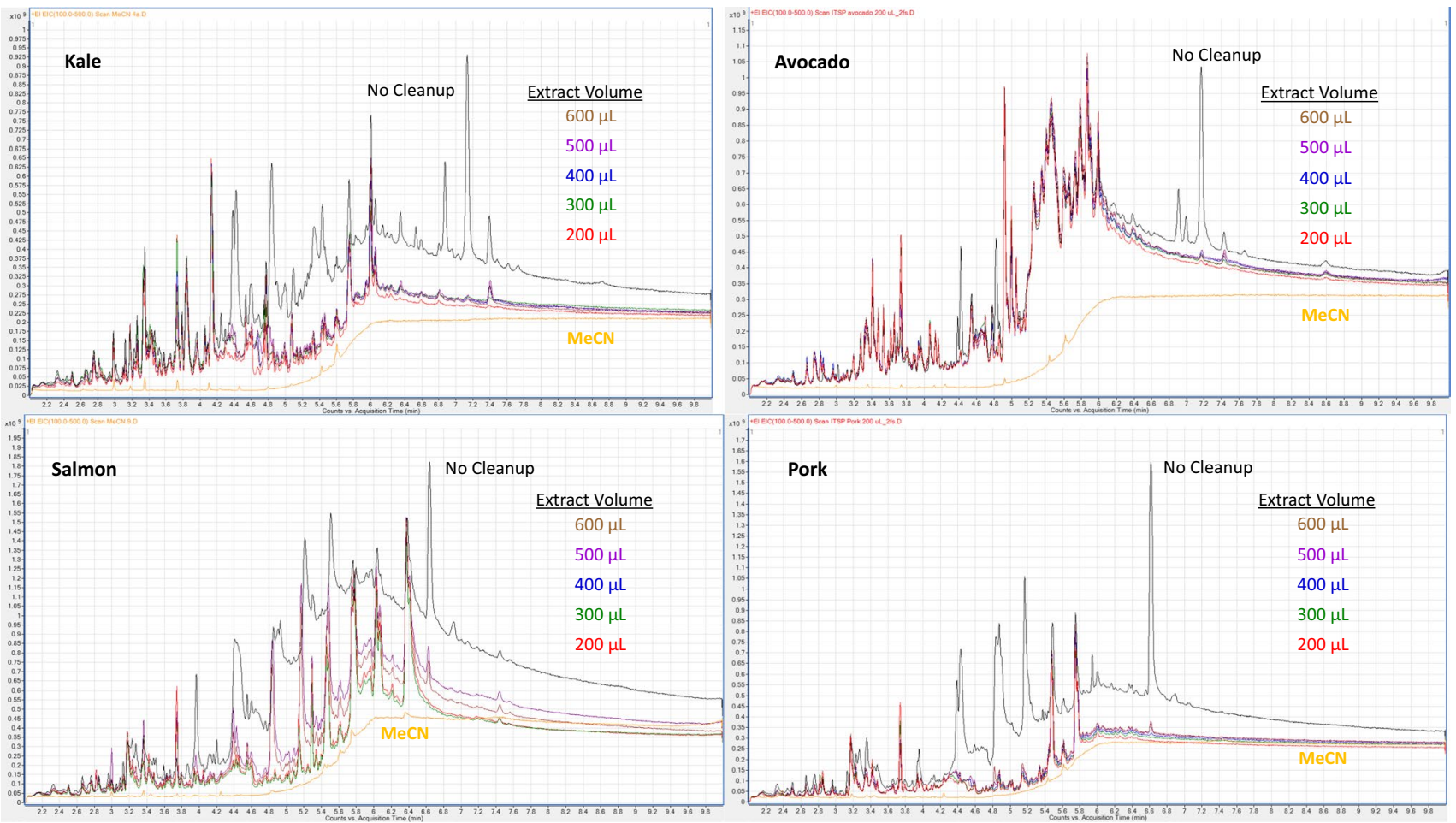

Fig. 2 Total ion chromatograms in full scan LPGC-MS of the QuEChERS extracts of 4 matrixes before and after cleanup with the 45 mg miniSPE cartridges using different extract load volumes

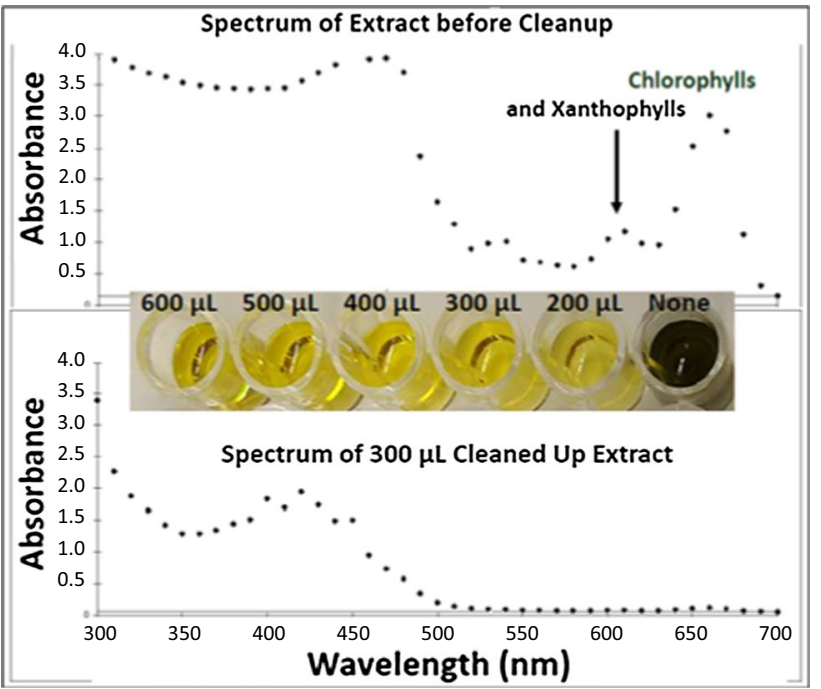

Fig. 3 Comparison of the UV-Vis spectra before and after cleanup of kale extracts using the $45 \mathrm{mg}$ anh. $\mathrm{MgSO}_{4} / \mathrm{PSA} / \mathrm{C}_{18} /$ CarbonX mini-SPE cartridges

Considering the notable cleanup efficiency observed in both UV-Vis and LPGC-MS for the $45 \mathrm{mg}$ mini-cartridges, especially at smaller load/elution volumes, and lack of retention of most analytes in QuEChERS extracts,

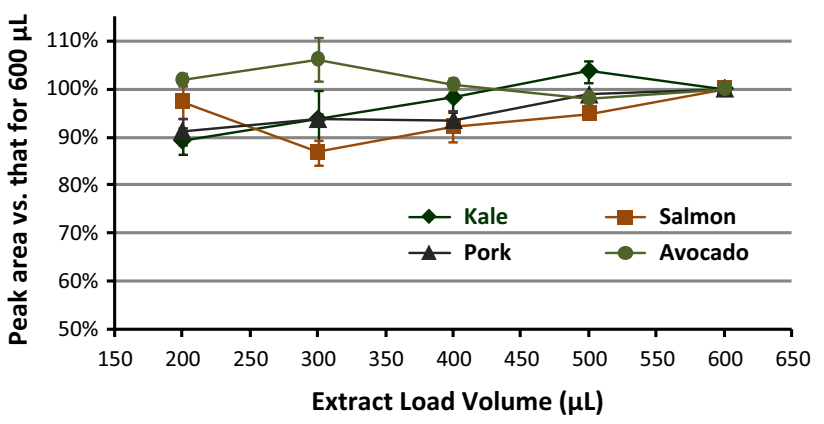

Fig. 4 Relative recoveries of bifenthrin in extracts of the 4 matrices (100 $\mathrm{ng} \mathrm{mL}^{-1}, n=3 \mathrm{each}$ ) after automated cleanup using the $45 \mathrm{mg}$ mini-cartridges

we chose to use $300 \mu \mathrm{L}$ load volumes with those mini-cartridges in the final method.

\section{Method Validation and Summation Integration}

For validation of the automated high-throughput cleanup and LPGC-MS/MS method, 10 representative food matrices were chosen using SANTE/11945/2015 [22] as a guide. The final method was conducted for two matrices per day in the following sequence: Day (1) Gala 


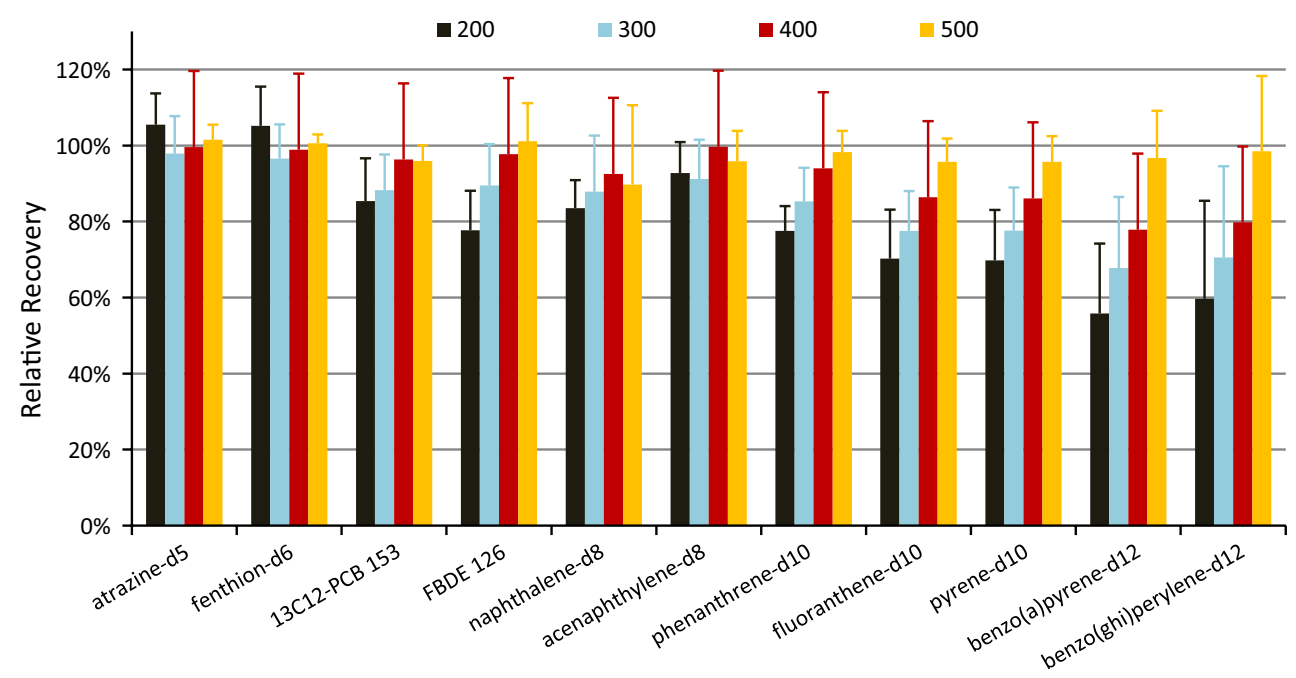

Fig. 5 Relative recoveries vs. the $600 \mu \mathrm{L}$ extract load volumes of the $11 \mathrm{IS}$ spiked at $100 \mathrm{ng} \mathrm{mL}^{-1}$ in the avocado, kale, pork, and salmon extracts using different load volumes with the $45 \mathrm{mg}$ mini-cartridges $(n=12$ each)

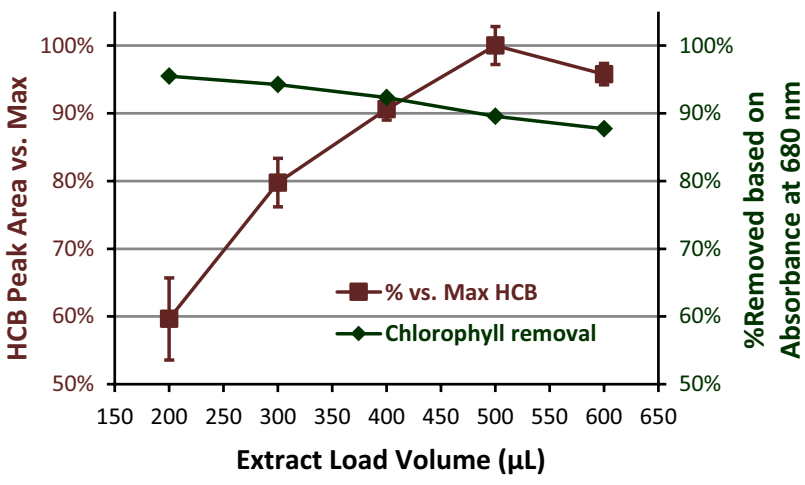

Fig. 6 Elution of hexachlorobenzene (HCB) and removal of chlorophyll from kale extracts passed through the $45 \mathrm{mg}$ anh. $\mathrm{MgSO}_{4} / \mathrm{PSA} /$ $\mathrm{C}_{18}$ /CarbonX mini-SPE cartridges

apple and kiwi; (2) carrot and kale; (3) navel orange and canned black olive; (4) wheat grain and dried basil; and (5) pork loin and salmon. QuEChERS has been extensively validated [24] and implemented in many labs [25], and to isolate the mini-SPE cleanup step in this study, initial QuEChERS extracts were spiked (or not) with the 97 analytes at $10,25,50$, and $100 \mathrm{ng} \mathrm{mL}^{-1}(n=4$ at each level and matrix). Each sequence began with seven blanks of each matrix, which were used for MM calibration standards, followed by the reagent blank and 16 spiked extracts of each matrix, for a total of 47 samples daily, and 235 altogether in 5 days sequentially. The LPGC-MS/ MS sequences were conducted each day overnight, which included an additional 7 RO standards conducted at the beginning and end of each sequence, plus a system suitability standard as the first injection and $3 \mathrm{MeCN}$ blanks injected after the $150 \mathrm{ng} \mathrm{mL}^{-1}\left(\mathrm{ng} \mathrm{g}^{-1}\right) \mathrm{RO}$ standards to check for carry over. A total of 65 LPGC-MS/MS analyses were conducted each night, and 325 within 5 days. The same injection liner and autotune parameters were used in each sequence.

Summation integration function start and stop times for each analyte were set after the conclusion of all 325 analyses by ensuring that all analyte peaks fell within the integration windows. The use of APs in LPGC-MS/MS led to highly consistent $t_{\mathrm{R}}$ and peak shapes for all analytes, and relatively few chemical interferences in the chromatograms for each MS/MS ion transition provided leeway to each side of the peak without significantly impacting the integrated peak areas. Figure 7 and Supplemental information show many examples of how the summation integration approach worked for different analytes and matrices. Dechlorane plus, (es)fenvalerate, permethrin, deltamethrin, cyfluthrin, and cypermethrin gave multiple peaks with the same ion transitions, several of which could have been integrated separately, but we chose to integrate them together as a single analyte. Sapozhnikova and Lehotay previously presented several examples of LPGC-MS/MS separations of different closely eluting analytes with isobaric ion transitions comparing columns from different manufacturers [17] (Figs. 4, 5, 6).

The Agilent summation function does not find the deflection point between unresolved peaks, which does not always occur at the exact same time in each chromatogram. Thus, benz(a)anthracene + chrysene and PCBs $118+123$ and $156+157$ could be distinguished individually by $t_{\mathrm{R}}$, but were integrated together because they closely co-eluted. We could have also integrated phenanthrene and anthracene together, but we chose to treat them separately and apply the default Agile2 integrator for purposes of comparison. 


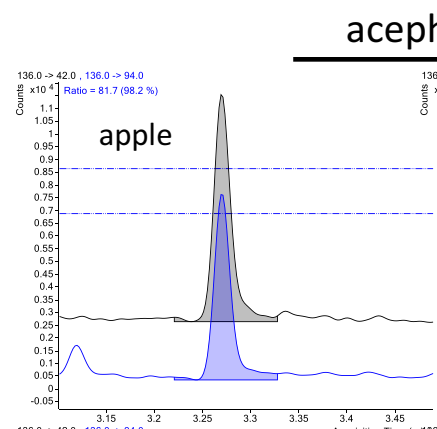

cephate
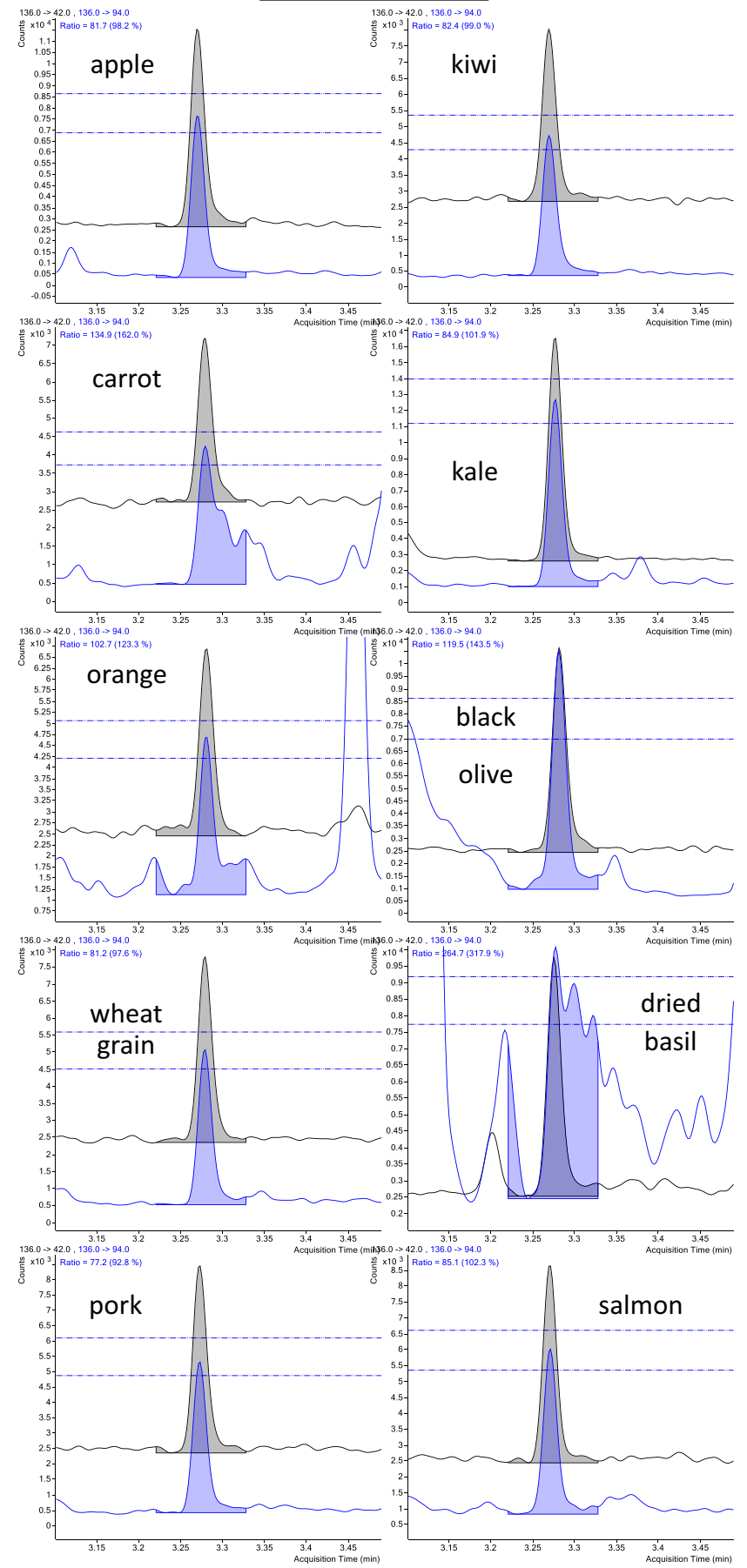

Fig. 7 Summation integration of $10 \mathrm{ng} \mathrm{mL}^{-1}$ spikes for acephate and pyriproxyfen in the 10 matrices over the course of 5 days. The qualifier ion met the $\pm 10 \%$ ratio relative to the fixed reference ratio for

Dozens of manual re-integrations each of phenanthrene and anthracene were needed, especially at the lowest levels, to correct the mistakes by the default program when it selected the wrong peak or used an inconsistent baseline. In the case of the other 107 analytes, IS, and QC standard,

\section{pyriproxyfen}
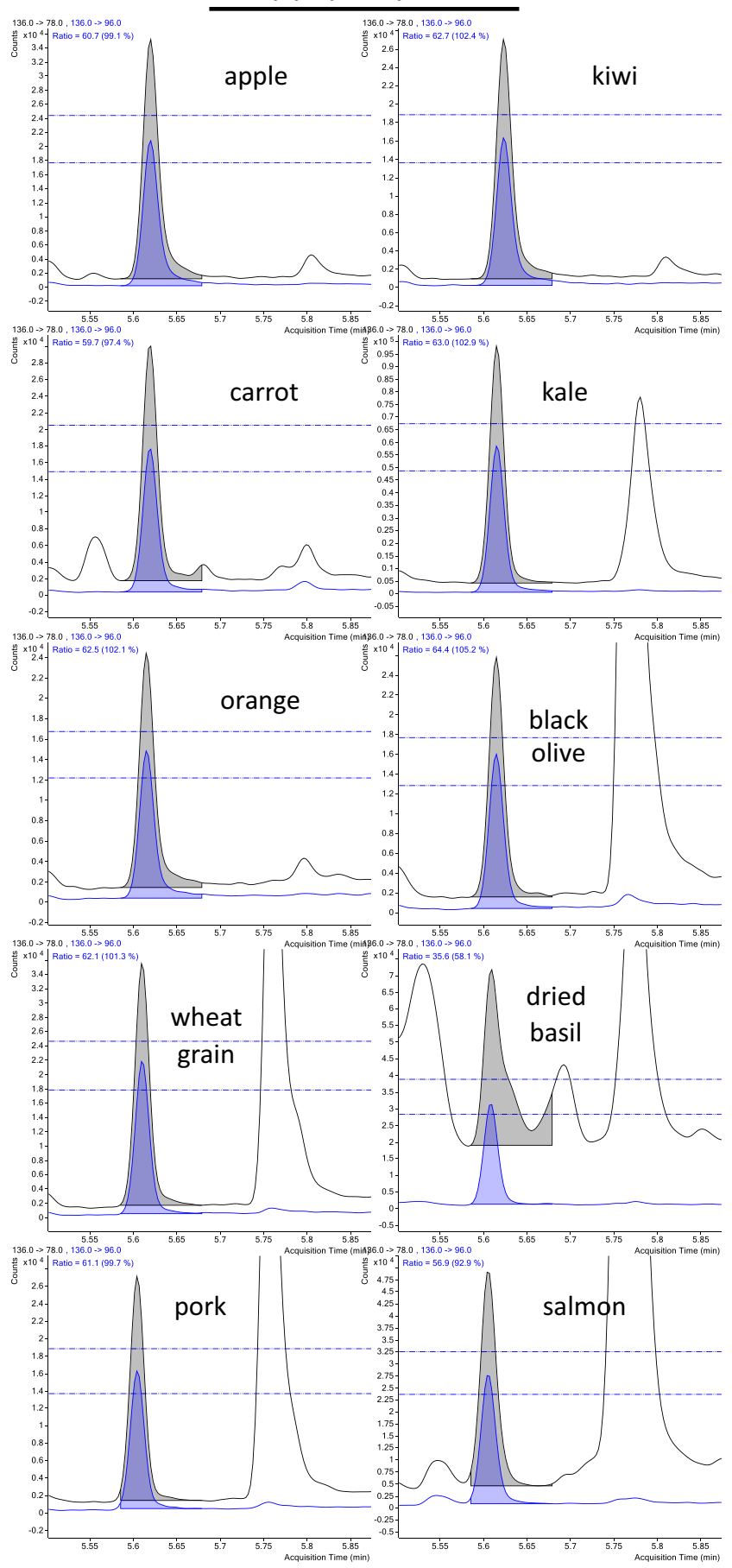

all, but acephate in black olive and dried basil in these examples, as shown by the horizontal lines

only spot-checking of integrations was conducted out of curiosity and no manual adjustments were made.

The 5-day validation experiment generated 66,950 data points (ion transition peaks) that would have taken an analyst several days to check that each peak was integrated 
(or not) appropriately and consistently. Using the summation integration function, the analyst spent only a few hours to set parameters, and all results were generated within a matter of minutes. Not only was human review of results not needed, the consistency of the summation integrations was superior to human capabilities and led to reliable quantitative results (see Supplemental information). Chemical interferences could be observed, especially in dried basil, orange, and black olive, but such interferants complicate peak integrations and worsen quality of results for any integration function.

Different means of post-run data processing batches were considered before settling on the final approach to report results calculated with and without normalization to the IS (see Table 1) using MM calibration standards for the same matrix. Potentially better results could have been obtained by narrowing the summation integration time windows to exactly accommodate the peak widths for each matrix, which were analyzed within hours of each other, but the wider windows that fully covered all peaks for all 325 injections were used in all cases. One drawback of the current software version was that the reported analyte $t_{\mathrm{R}}$ was the midpoint between the integration start and stop times rather than the actual apex of the peak, and this should be corrected in the future.

\section{Validation Results}

Table 3 lists the compiled results with normalization to the IS for all 94 analytes (including pairs) in the 10 matrices spiked at different levels ( $n=40$ each), as well as overall results for all levels and matrices $(n=160)$. Underlined font emphasizes when overall results yielded $100 \% \pm 10 \%$ recoveries, and bold text indicates when $<70$ or $>120 \%$ recovery and $\geq 25 \% \mathrm{RSD}$ were obtained. When using the IS, 42 out of 97 analytes gave 90-110\% recoveries and $\leq 10 \% \mathrm{RSD}$, which is exceptional considering that 230 injections of 10 complex matrices at ultra-trace spiking levels were made without manual re-integrations or instrument maintenance over 5 days sequentially. For comparison, the overall average recoveries and RSD for each analyte without normalization to the IS are also presented in Table 3. Clearly, the IS were needed to provide better precision in the results, and to account for partial retention of the larger PAHs. For nearly all pesticides and most FRs and PCBs, the IS only helped to account for volume fluctuations in the mini-SPE cleanup step. The variability of the elution volume can be observed in Fig. 1, and Table 3 shows how well the IS compensated for these fluctuations from day-to-day and matrix-to-matrix. The differing amounts of water in the different matrices and initial and final extracts also likely contributed substantially to the variations without the IS.
When using the IS, only three analytes (PBEB, benz(a) anthracene + chrysene, and thiabendazole) had $<70 \%$ overall average recoveries $(64,68$, and $67 \%$, respectively) and only six analytes (naphthalene, TPP, TBCO, fenpropathrin, deltamethrin, and thiabendazole) had overall RSDs $>25 \%$. TPP and naphthalene were ubiquitous in all of the reagent blanks at varying concentrations averaging 7 and $75 \mathrm{ng} \mathrm{mL}^{-1}$, respectively, and similar levels in the final matrix extracts. Analytical conditions for fenpropathrin were not optimal, and an interferant averaging $18 \mathrm{ng} \mathrm{g}^{-1}$ equivalent response adversely affected its results. Deltamethrin is known to degrade in the injection inlet [20], which was the main cause of its more variable results, which was also the case for methoxychlor to a lesser extent. Last, thiabendazole and TBCO (and TBECH) gave very broad chromatographic peaks. Despite the inconsistent results for those six analytes, the chromatographic peak shapes and results were very good for other notoriously difficult analytes in GC, such as methamidophos, acephate, omethoate, dimethoate, carbofuran, chlorothalonil, imazalil, and myclobutanil (see Supplemental information). In fact, dimethoate was among those analytes that gave the best results, and cyfluthrin was another analyte that gave surprisingly high quality results.

Despite the much greater variability, the overall recoveries without normalization to the IS were the same as when using the IS except PBEB and PCB 169 were 67 and $63 \%$, respectively, and 8 PAHs had 14-63\% uncompensated recoveries. As stated earlier, the $1 \mathrm{mg}$ CarbonX was probably the cause for the lower recoveries of structurally (co-) planar analytes, but the isotopically labeled IS worked well to improve accuracy in all cases, albeit an ideal IS was not obtained for benz(a)anthracene + chrysene or benzo $(b+k)$ fluoranthene.

In addition to its high quality of results, the automated mini-SPE + LPGC-MS/MS method provided excellent ruggedness in the analysis of all 325 samples. Due to the clean extracts, small injection volumes, mega-bore analytical column, and use of APs, the same injection liner and septum was used for all 325 injections in 10 matrices over the course of 5 days. A picture of the used liner and septum appears in Supplemental information. Even the fatty salmon matrix, which was analyzed last, showed very good peak shapes and perfectly linear calibration with the same high quality results as the other matrices (see Supplemental information).

\section{Matrix Effects (MEs)}

MEs were measured both with and without normalization of integrated peak areas to the IS. As in the case of recoveries, the IS helped to greatly reduce imprecision in the measurements. As shown in Supplemental information, the PCBs, 
Table 3 Average mini-SPE \% recoveries (and \%RSD) of the 94 analytes (including three pairs) in 10 matrices at four spiking levels $(n=40$ at each level, and $n=160$ overall) in the validation study

\begin{tabular}{|c|c|c|c|c|c|c|c|}
\hline Nos. & Analyte & $\begin{array}{l}10 \\
\mathrm{ng} \mathrm{mL}^{-1}\end{array}$ & $\begin{array}{l}25 \\
\mathrm{ng} \mathrm{mL}\end{array}$ & $\begin{array}{l}50 \\
\mathrm{ng} \mathrm{mL}\end{array}$ & $\begin{array}{l}100 \\
\mathrm{ng} \mathrm{mL}^{-1}\end{array}$ & Overall vs. IS & Overall w/o IS \\
\hline \multicolumn{8}{|c|}{ Pesticides } \\
\hline 1 & Acephate & $98(16)$ & $90(14)$ & $93(20)$ & $92(20)$ & $95(17)$ & $103(41)$ \\
\hline 2 & Aldrin & $91(12)$ & $89(10)$ & $91(11)$ & $93(8)$ & $90(11)$ & $93(24)$ \\
\hline 3 & Atrazine & $99(8)$ & $95(5)$ & $96(3)$ & $97(4)$ & $\underline{98(6)}$ & $104(26)$ \\
\hline 4 & Bifenthrin & $93(8)$ & $91(5)$ & $93(9)$ & $93(9)$ & $\underline{93(9)}$ & $99(30)$ \\
\hline 5 & Carbofuran & $102(11)$ & $97(9)$ & $98(9)$ & $101(11)$ & $101(11)$ & $106(34)$ \\
\hline 6 & Carbophenothion & $99(10)$ & $94(5)$ & $97(9)$ & $97(9)$ & $\underline{98(10)}$ & $105(32)$ \\
\hline 7 & Chlorothalonil & $95(16)$ & 87 (14) & $88(16)$ & $90(17)$ & $91(16)$ & $97(31)$ \\
\hline 8 & Chlorpyrifos & $96(8)$ & $93(4)$ & $95(4)$ & $97(4)$ & $\underline{96(6)}$ & $101(25)$ \\
\hline 9 & Coumaphos & $94(10)$ & $91(8)$ & $92(12)$ & $91(11)$ & $93(11)$ & $101(30)$ \\
\hline 10 & Cyfluthrin & $92(8)$ & $91(7)$ & $92(10)$ & $92(9)$ & $\underline{92(9)}$ & $100(29)$ \\
\hline 11 & Cypermethrin & 95 (14) & $88(8)$ & $92(13)$ & $91(11)$ & $93(13)$ & $100(37)$ \\
\hline 12 & Cyprodinil & $87(8)$ & $86(5)$ & $87(7)$ & $88(7)$ & $88(7)$ & $93(28)$ \\
\hline 13 & Deltamethrin & $111(\mathbf{5 0})$ & $92(22)$ & $93(19)$ & $88(22)$ & $98(\mathbf{3 4})$ & $119(59)$ \\
\hline 14 & $o, p^{\prime}-\mathrm{DDE}$ & $94(7)$ & $91(5)$ & $92(5)$ & $94(4)$ & $\underline{93(6)}$ & $98(24)$ \\
\hline 15 & $p, p^{\prime}-\mathrm{DDE}$ & $92(8)$ & $89(7)$ & $92(5)$ & $93(4)$ & $91(7)$ & $98(30)$ \\
\hline 16 & Diazinon & $101(10)$ & $96(7)$ & $95(5)$ & $97(5)$ & $\underline{98(8)}$ & $105(29)$ \\
\hline 17 & Dicrotophos & $109(20)$ & $97(11)$ & $94(9)$ & $96(9)$ & $101(15)$ & $107(35)$ \\
\hline 18 & Dimethoate & $101(8)$ & $96(5)$ & $96(6)$ & $98(6)$ & $\underline{99(7)}$ & $106(30)$ \\
\hline 19 & Diphenylamine & $102(15)$ & $97(8)$ & $98(8)$ & $100(6)$ & $100(11)$ & $106(25)$ \\
\hline 20 & Endosulfan I & $98(14)$ & $93(6)$ & $94(6)$ & $95(6)$ & $\underline{95(9)}$ & $100(26)$ \\
\hline 21 & Endosulfan II & $97(8)$ & $93(8)$ & $94(8)$ & $95(6)$ & $\underline{96(8)}$ & $102(28)$ \\
\hline 22 & Endosulfan sulfate & $96(18)$ & $95(9)$ & $96(11)$ & $97(8)$ & $98(13)$ & $104(31)$ \\
\hline 23 & Esfenvalerate & $96(11)$ & $91(8)$ & $93(12)$ & $93(11)$ & $94(12)$ & $103(33)$ \\
\hline 24 & Ethalfluralin & $101(12)$ & $96(9)$ & $96(10)$ & $97(7)$ & $\underline{98(10)}$ & $105(25)$ \\
\hline 25 & Ethoprop & $99(24)$ & $98(12)$ & $97(9)$ & $98(8)$ & $98(15)$ & $104(28)$ \\
\hline 26 & Fenpropathrin & 91 (70) & $93(\mathbf{3 4})$ & $89(\mathbf{2 6})$ & 89 (17) & $92(\mathbf{4 1})$ & $119(90)$ \\
\hline 27 & Fipronil & 105 (12) & $98(10)$ & $99(13)$ & $98(12)$ & $101(12)$ & $109(32)$ \\
\hline 28 & Flutriafol & $99(9)$ & $95(5)$ & $96(11)$ & $96(9)$ & $\underline{98(9)}$ & $105(32)$ \\
\hline 29 & Heptachlor & $94(14)$ & $92(13)$ & $93(11)$ & $94(10)$ & $94(12)$ & $99(25)$ \\
\hline 30 & Heptachlor epoxide & $98(9)$ & $95(8)$ & $95(6)$ & $97(5)$ & $97(8)$ & $102(23)$ \\
\hline 31 & Heptenophos & $103(15)$ & $96(10)$ & 97 (12) & $100(8)$ & $100(13)$ & $105(27)$ \\
\hline 32 & Hexachlorobenzene & $83(20)$ & $87(10)$ & $89(11)$ & $90(11)$ & $86(14)$ & $88(26)$ \\
\hline 33 & Imazalil & $83(\mathbf{2 1})$ & $81(13)$ & $83(14)$ & $83(10)$ & $83(15)$ & 87 (37) \\
\hline 34 & Kresoxim-methyl & $100(10)$ & $96(6)$ & $97(8)$ & $98(7)$ & $\underline{99(8)}$ & $106(29)$ \\
\hline 35 & Lindane & $100(11)$ & 97 (7) & 97 (7) & $99(6)$ & $\underline{99(9)}$ & $104(23)$ \\
\hline 36 & Methamidophos & $97(16)$ & $91(15)$ & $92(16)$ & $95(16)$ & $96(16)$ & $103(35)$ \\
\hline 37 & Methoxychlor & $95(\mathbf{2 5})$ & $92(23)$ & $94(\mathbf{2 6})$ & $91(25)$ & $93(25)$ & $101(39)$ \\
\hline 38 & Mirex & $83(9)$ & $82(10)$ & $85(12)$ & $85(12)$ & $83(11)$ & $88(33)$ \\
\hline 39 & Myclobutanil & 99 (7) & $95(5)$ & $96(9)$ & $96(8)$ & $\underline{98(8)}$ & $105(30)$ \\
\hline 40 & cis-Nonachlor & $96(9)$ & $91(6)$ & $92(6)$ & $94(6)$ & $\underline{94(7)}$ & $101(28)$ \\
\hline 41 & trans-Nonachlor & $93(8)$ & $91(6)$ & $92(6)$ & $94(5)$ & $\underline{93(7)}$ & $98(25)$ \\
\hline 42 & Omethoate & $103(15)$ & $96(12)$ & $90(20)$ & $93(15)$ & $97(16)$ & $106(35)$ \\
\hline 43 & $o$-Phenylphenol & $102(19)$ & $97(11)$ & $98(11)$ & $100(8)$ & $100(14)$ & $104(30)$ \\
\hline 44 & Penconazole & $94(8)$ & $92(4)$ & $93(8)$ & $94(7)$ & $\underline{94(7)}$ & $101(29)$ \\
\hline 45 & Pentachlorothioanisole & $93(15)$ & $92(10)$ & $94(11)$ & $96(9)$ & $93(11)$ & $96(22)$ \\
\hline 46 & Permethrin & $92(16)$ & $92(7)$ & $93(10)$ & $92(8)$ & $93(11)$ & $101(36)$ \\
\hline
\end{tabular}


Table 3 continued

\begin{tabular}{|c|c|c|c|c|c|c|c|}
\hline Nos. & Analyte & $\begin{array}{l}10 \\
\mathrm{ng} \mathrm{mL}\end{array}$ & $\begin{array}{l}25 \\
\mathrm{ng} \mathrm{mL}\end{array}$ & $\begin{array}{l}50 \\
\text { ng mL }\end{array}$ & $\begin{array}{l}100 \\
\mathrm{ng} \mathrm{mL}^{-1}\end{array}$ & Overall vs. IS & Overall w/o IS \\
\hline 47 & Piperonyl butoxide & $96(8)$ & $92(6)$ & $94(10)$ & $93(9)$ & $\underline{95(9)}$ & $103(31)$ \\
\hline 48 & Propargite & $101(15)$ & $94(9)$ & $95(14)$ & $97(14)$ & $97(16)$ & $103(30)$ \\
\hline 49 & Pyridaben & $93(8)$ & $89(6)$ & $91(11)$ & $91(9)$ & $\underline{92(10)}$ & $100(31)$ \\
\hline 50 & Pyriproxyfen & $93(8)$ & $91(6)$ & $92(11)$ & $92(9)$ & $93(9)$ & $102(31)$ \\
\hline 51 & Tebuconazole & $93(14)$ & $87(9)$ & $90(13)$ & $89(10)$ & $91(12)$ & $100(34)$ \\
\hline 52 & Tetraconazole & 99 (7) & $97(5)$ & $97(7)$ & $98(7)$ & $\underline{99(7)}$ & $105(27)$ \\
\hline 53 & Thiabendazole & $63(31)$ & $64(25)$ & $69(26)$ & $70(25)$ & $67(27)$ & $71(41)$ \\
\hline 54 & Tribufos & $95(11)$ & $88(7)$ & $91(11)$ & $90(8)$ & $\underline{92(10)}$ & $99(32)$ \\
\hline \multicolumn{8}{|l|}{ FRs } \\
\hline 1 & BDE 183 & $101(36)$ & $100(18)$ & $100(13)$ & $101(10)$ & $100(21)$ & $76(37)$ \\
\hline 2 & Dechlorane plus (syn + anti) & $99(12)$ & $99(14)$ & $99(11)$ & $100(10)$ & $98(11)$ & $80(32)$ \\
\hline 3 & PBB 153 & $103(11)$ & $101(10)$ & $103(9)$ & $105(9)$ & $\underline{102(10)}$ & $81(31)$ \\
\hline 4 & PBEB & $63(20)$ & $63(11)$ & $67(10)$ & $67(15)$ & $64(15)$ & $67(33)$ \\
\hline 5 & PBT & $92(11)$ & $91(9)$ & $93(10)$ & $96(12)$ & $92(11)$ & $72(29)$ \\
\hline 6 & TBB & $86(10)$ & $85(7)$ & $87(6)$ & $87(8)$ & $86(8)$ & 69 (33) \\
\hline 7 & TBCO & $102(\mathbf{4 3})$ & $93(\mathbf{2 8})$ & $91(24)$ & $93(21)$ & $96(30)$ & $104(43)$ \\
\hline 8 & TBECH & $100(25)$ & $94(17)$ & $96(16)$ & $95(12)$ & $97(18)$ & $104(32)$ \\
\hline 9 & TBNPA & $106(\mathbf{2 6})$ & $98(14)$ & $98(16)$ & $100(11)$ & $101(18)$ & $103(34)$ \\
\hline 10 & TBX & $70(12)$ & $69(8)$ & $73(7)$ & $74(10)$ & $70(11)$ & $73(26)$ \\
\hline 11 & TCEP & $101(5)$ & $97(4)$ & $96(3)$ & $98(5)$ & $\underline{99(5)}$ & $105(28)$ \\
\hline 12 & TCPP & $100(7)$ & $96(4)$ & $97(3)$ & $98(4)$ & $\underline{99(6)}$ & $105(28)$ \\
\hline 13 & TDCPP & $101(9)$ & $97(7)$ & $98(11)$ & $98(10)$ & $\underline{99(10)}$ & $107(32)$ \\
\hline 14 & Triphenylphosphate & $90(\mathbf{3 9})$ & $96(27)$ & $98(25)$ & $98(23)$ & $96(\mathbf{2 8})$ & $105(46)$ \\
\hline \multicolumn{8}{|l|}{ PAHs } \\
\hline 1 & Acenaphthene & $100(16)$ & $99(6)$ & $100(5)$ & $101(5)$ & $\underline{100(9)}$ & $100(27)$ \\
\hline 2 & Acenaphthalene & $97(6)$ & $96(5)$ & $97(3)$ & $98(3)$ & $\underline{97(5)}$ & $99(22)$ \\
\hline 3 & Anthracene & $100(11)$ & $92(5)$ & $95(5)$ & $96(4)$ & $\underline{96(8)}$ & $85(27)$ \\
\hline 4 & Benz(a)anthracene + Chrysene & $69(13)$ & $66(12)$ & $67(13)$ & $68(13)$ & $68(13)$ & $40(44)$ \\
\hline 5 & Benzo(a)pyrene & $109(9)$ & $97(6)$ & $95(3)$ & $97(4)$ & $100(8)$ & $22(53)$ \\
\hline 6 & Benzo $(b+k)$ fluoranthene & $123(6)$ & $115(5)$ & $113(3)$ & $115(3)$ & $117(6)$ & $27(48)$ \\
\hline 7 & $\operatorname{Benzo}(\mathrm{g}, \mathrm{h}, \mathrm{i})$ perylene & $120(15)$ & $103(8)$ & $100(4)$ & $102(4)$ & $106(12)$ & $14(64)$ \\
\hline 8 & Dibenz(ah)anthracene & $100(13)$ & $84(8)$ & $82(5)$ & $82(5)$ & $87(13)$ & $19(58)$ \\
\hline 9 & Fluoranthene & $104(5)$ & $97(4)$ & $96(3)$ & $97(3)$ & $\underline{99(5)}$ & $63(32)$ \\
\hline 10 & Fluorene & $115(17)$ & $116(10)$ & $113(7)$ & $114(8)$ & $114(12)$ & $98(24)$ \\
\hline 11 & Indeno( $(1,2,3-c, d)$ pyrene & $117(14)$ & $109(12)$ & $108(8)$ & $114(12)$ & $113(12)$ & $17(61)$ \\
\hline 12 & Naphthalene & $128(95)$ & $118(\mathbf{7 8})$ & $117(\mathbf{2 9})$ & $108(\mathbf{2 8})$ & $115(63)$ & $114(71)$ \\
\hline 13 & Phenanthrene & $114(16)$ & $101(5)$ & $99(4)$ & $99(3)$ & $104(11)$ & $89(30)$ \\
\hline 14 & Pyrene & $108(6)$ & $99(5)$ & $97(2)$ & $98(3)$ & $\underline{101(6)}$ & $57(36)$ \\
\hline \multicolumn{8}{|l|}{ PCBs } \\
\hline 1 & PCB 77 & 97 (17) & $96(7)$ & $97(8)$ & $98(9)$ & $97(11)$ & $85(29)$ \\
\hline 2 & PCB 81 & $100(8)$ & $96(8)$ & $97(6)$ & 99 (7) & $\underline{98(8)}$ & $85(27)$ \\
\hline 3 & PCB 105 & $106(7)$ & $104(8)$ & 107 (6) & $108(6)$ & $106(7)$ & $91(26)$ \\
\hline 4 & PCB 114 & $106(5)$ & $104(7)$ & $106(7)$ & $108(8)$ & $\underline{106(7)}$ & $90(26)$ \\
\hline 5 & PCB $118+123$ & $103(8)$ & $102(7)$ & $106(7)$ & $107(7)$ & $\underline{104(8)}$ & $89(28)$ \\
\hline 6 & PCB 126 & $88(12)$ & $85(9)$ & $87(11)$ & $88(11)$ & $86(11)$ & $75(29)$ \\
\hline 7 & PCB $156+157$ & $100(8)$ & $98(8)$ & $100(9)$ & $101(9)$ & $99(9)$ & 85 (26) \\
\hline 8 & PCB 167 & $98(7)$ & $96(8)$ & $100(8)$ & $100(9)$ & $\underline{97(9)}$ & $83(28)$ \\
\hline 9 & PCB 169 & 75 (19) & $72(13)$ & $75(13)$ & $74(14)$ & $74(15)$ & $63(30)$ \\
\hline
\end{tabular}


Table 3 continued

\begin{tabular}{llclllll}
\hline Nos. & Analyte & $\begin{array}{l}10 \\
\mathrm{ng} \mathrm{mL}\end{array}$ & $\begin{array}{l}25 \\
\mathrm{ng} \mathrm{mL} \mathrm{mL}^{-1}\end{array}$ & $\begin{array}{l}50 \\
\mathrm{ng} \mathrm{mL} \mathrm{mL}^{-1}\end{array}$ & $\begin{array}{l}\text { lo0 } \\
\mathrm{ng} \mathrm{mL}\end{array}$ & Overall vs. IS & Overall w/o IS \\
\hline 10 & PCB 170 & $98(8)$ & $97(9)$ & $99(9)$ & $100(10)$ & $\underline{98(9)}$ & $83(29)$ \\
11 & PCB 180 & $100(8)$ & $95(9)$ & $99(9)$ & $98(11)$ & $96(10)$ & $82(28)$ \\
12 & PCB 189 & $92(16)$ & $92(12)$ & $91(16)$ & $93(15)$ & $91(15)$ & $76(25)$ \\
\hline
\end{tabular}

Bold text indicates recovery $<70 \%$ or RSD $>25 \%$

Underlining emphasizes overall recoveries of $90-110 \%$ and RSD of $10 \%$ or less

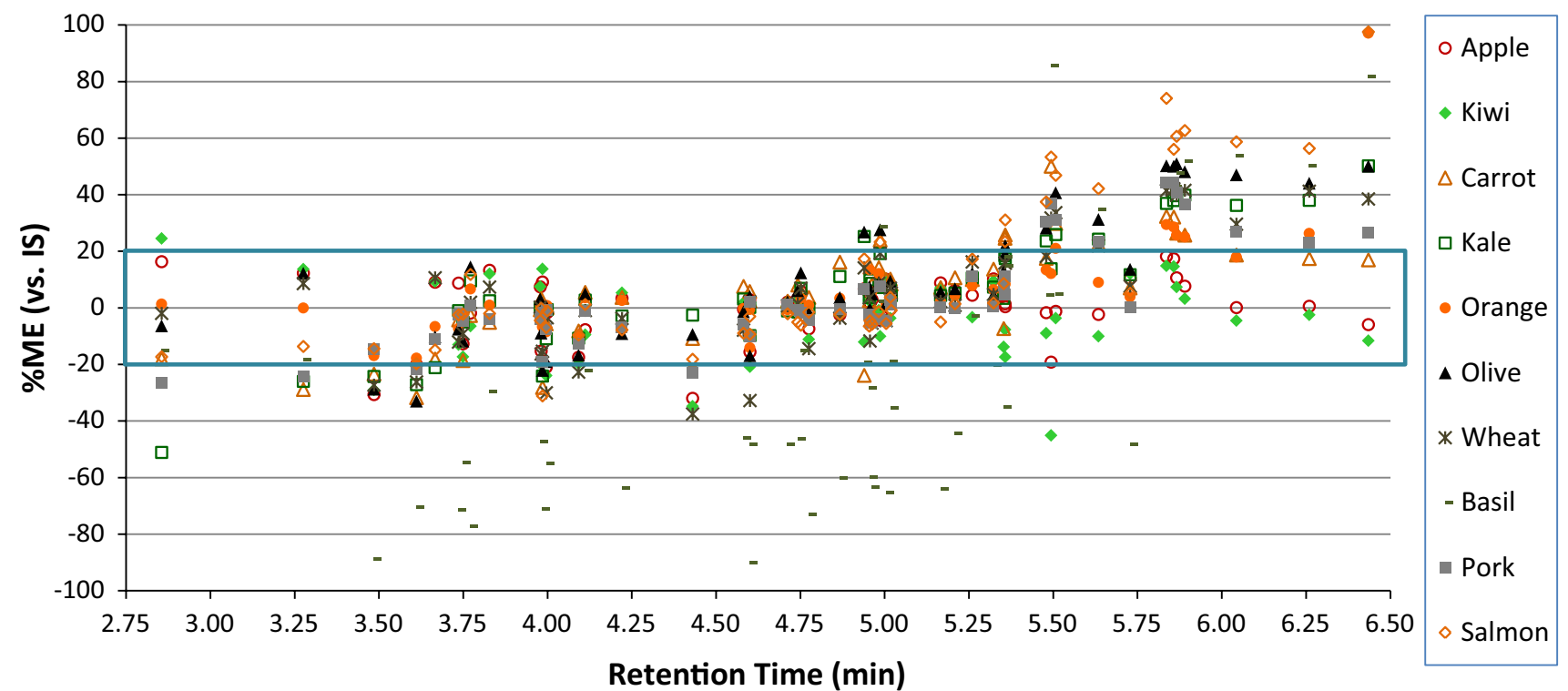

Fig. 8 Matrix effects (MEs) of the 54 pesticides plotted vs. $t_{\mathrm{R}}$ in LPGC-MS/MS using APs after automated mini-SPE cleanup of QuEChERS extracts of 10 matrixes

PAHs, and nearly all FRs did not undergo MEs $(<| \pm 20 \%|)$, mainly due to their nonpolar nature (relatively polar analytes are more susceptible to MEs). Figure 8 shows MEs in the case of pesticides in each matrix plotted vs. increasing $t_{\mathrm{R}}$. When MEs $<1 \pm 20 \%$ occur (shown by the box in the figure), then RO standards can be used to yield similar results as MM calibration standards. Despite the common practice in residue analysis to use MM standards, they require storage of many blank matrices and take more time for sample preparation, plus the extra materials, labor, and costs involved, than simply preparing RO calibration standards. Use of MM standards also causes more matrixes to be introduced to the instrument during analytical batches, as well as complications to match given matrices when different commodities are analyzed in the same sequence. Calibration using RO standards is more advantageous in practice, provided that MEs do not lead to unacceptable accuracy.

Unlike LC-MS/MS in which ion suppression occurs due to MEs [26], signal enhancement commonly occurs to susceptible analytes in GC analysis [27]. However, as shown in
Fig. 8, basil induced a severe response diminishment effect, presumably due to the sheer amount of co-extractives from the dried herb even after mini-SPE cleanup. Herbs and spices are unique matrices that require $\mathrm{MM}$ calibration even after extensive cleanup in any GC-MS or LC-MS method. With few exceptions between 2.5 and $5.5 \mathrm{~min} t_{\mathrm{R}}$, MEs for the analytes fell within $I \pm 20 \%$ (see Fig. 8). As described previously [19], the APs can overcome MEs for the analytes with $t_{\mathrm{R}}$ less than about permethrin, but a good AP for the late-eluting pyrethroids has not been found yet. The current mixture of APs (and their breakdown products) is too volatile to coelute with the late-eluting analytes, which is shown clearly in Fig. 8. In this study, 10 pesticides underwent $>20 \%$ MEs for all matrices except the least complex fruits and vegetables (apple, kiwi, and carrot). These analytes consist of coumaphos, pyridaben, methoxychlor, and the pyrethroids: bifenthrin, fenpropathrin, permethrin, cyfluthrin, cypermethrin, esfenvalerate, and deltamethrin). Similarly, late-eluting PCBs, PAHs, and FRs yielded insignificant MEs, especially when using IS with $t_{\mathrm{R}}$ near the analytes. Despite the 
nonpolar nature of these PCBs, PAHs, and FRs, MEs were observed to a greater extent without normalization to the IS, which leads us to hypothesize that use of an appropriate IS for pyrethroids may solve this problem with excessive MEs.

\section{Conclusions}

The automated mini-SPE cleanup coupled with LPGCMS/MS analysis not only achieved high quality results for diverse type of analytes and foods, the approach also enabled reliable, high-throughput operations without much labor or instrument maintenance. The use of a state-of-theart GC-MS/MS instrument permitted injection of merely $1 \mathrm{mg}$ sample equivalent while still achieving $<5 \mathrm{ng} \mathrm{g}^{-1}$ LOQs for all analytes (LOQ $<0.5 \mathrm{ng} \mathrm{g}^{-1}$ for most analytes). The use of APs also helped lead to very consistent $t_{\mathrm{R}}$ and peak shape for the analytes, even after hundreds of sample injections, which enabled use of summation function integration to eliminate human review of chromatographic peak integrations. This data processing approach saved many hours of analyst time, which is usually the rate limiting in real-world practice.

Using the final method in unattended instrument operation, two analysts conducted the full validation study involving 235 samples in 5 days. One of the analysts performed initial QuEChERS extractions, and because we do not have barcode reading, the other analyst's time in the lab was spent labeling vials and entering sample names into long sequences. In the final method, the automated mini-SPE step took $8 \mathrm{~min}$ per sample, and the LPGC-MS/MS step was 13 min including oven re-equilibration. In the future, we intend to substantially reduce the time needed for both operations.

Last, some incurred analytes were quantified and identified $>10 \mathrm{ng} \mathrm{g}^{-1}$ in the tested commodities: imazalil (1243 $\left.\mathrm{ng} \mathrm{g}^{-1}\right)$ and thiabendazole $\left(640 \mathrm{ng} \mathrm{g}^{-1}\right)$ were detected in the oranges, $p, p^{\prime}$-DDE $\left(56 \mathrm{ng} \mathrm{g}^{-1}\right)$ was determined in kale, and diphenylamine $\left(17 \mathrm{ng} \mathrm{g}^{-1}\right)$ and thiabendazole $\left(16 \mathrm{ng} \mathrm{g}^{-1}\right)$ were detected in the Gala apple. A few other pesticides were identified between the $5 \mathrm{ng} \mathrm{g}^{-1}$ lowest calibrated level and $10 \mathrm{ng} \mathrm{g}^{-1}$ reporting level. The practical application of this automated approach has been demonstrated to meet real-world monitoring needs.

Acknowledgments Thanks to CTC Analytics for the firmware, communications board, software, and training to operate the robotic liquid handler. Thanks also to ITSP Solutions and Hill Laboratories for devising initial methods as a template. Lijun Han's sabbatical funding was provided by the China Scholarship Council (CSC).

\section{Compliance with Ethical Standards}

Conflict of interest All authors declare no conflicts of interest. This article does not contain any studies with human participants or animals performed by any of the authors.
Open Access This article is distributed under the terms of the Creative Commons Attribution 4.0 International License (http://creativecommons.org/licenses/by/4.0/), which permits unrestricted use, distribution, and reproduction in any medium, provided you give appropriate credit to the original author(s) and the source, provide a link to the Creative Commons license, and indicate if changes were made.

\section{References}

1. World Trade Organization (2014) International trade statistics 2014

2. European Food Safety Authority (2015) The 2013 European Union report on pesticide residues in food. EFSA J 13:1-169

3. USDA Agricultural Marketing Service (2014) Pesticide data program annual summary, calendar year 2014. https://www.ams. usda.gov/sites/default/files/media/2014\%20PDP\%20Annual\%20 Summary.pdf

4. Food Safety Modernization Act (FSMA). http://www.gpo.gov/ fdsys/pkg/PLAW-111publ353/pdf/PLAW-111pub1353.pdf

5. Global MRL database. https://www.globalmrl.com/

6. European Food Safety Authority (EFSA) Pesticide MRL harmonisation programme. http://www.efsa.europa.eu/en/mrls/ mrlharmonisation

7. Lehotay SJ, Sapozhnikova Y, Mol HGJ (2015) Current issues involving screening and identification of chemical contaminants in foods by mass spectrometry. TrAC. Trends Anal Chem 69:62-75

8. Anastassiades M, Lehotay SJ, Stajnbaher D, Schenck FJ (2003) Fast and easy multiresidue method employing acetonitrile extraction/partitioning and "dispersive solid-phase extraction" for the determination of pesticide residues in produce. J AOAC Int 86:412-431

9. Gonzalez-Curbelo MA, Socas-Rodriguez B, Herrera-Herrera AV, Gonzalez-Salamo J, Hernandez-Borges J, Rodriguez-Delgado MA (2015) Evolution and applications of the QuEChERS method. TrAC. Trends Anal Chem 71:169-185

10. Sapozhnikova Y, Lehotay SJ (2013) Multi-class, multi-residue analysis of pesticides, polychlorinated biphenyls, polycyclic aromatic hydrocarbons, polybrominated diphenyl ethers and novel flame retardants in fish using fast, low-pressure gas chromatography-tandem mass spectrometry. Anal Chim Acta 758:80-92

11. Raynie D (2016) Trends in sample preparation. LCGC North Am 34:174-188

12. Morris BD, Schriner RB (2015) Development of an automated column solid-phase extraction cleanup of QuEChERS extracts, using a zirconia-based sorbent, for pesticide residue analyses by LC-MS/MS. J Agric Food Chem 63:5107-5119

13. Han L, Sapozhnikova Y, Lehotay SJ (2014) Streamlined sample cleanup using combined dispersive solid-phase extraction and invial filtration for analysis of pesticides and environmental pollutants in shrimp. Anal Chim Acta 827:40-46

14. Alder L, Greulich K, Kempe G, Vieth B (2006) Residue analysis of 500 high priority pesticides: better by GC-MS or LC-MS/ MS? Mass Spectrom. Rev. 25:838-865

15. Wang J, Chow W, Chang J, Wong JW (2014) Ultrahigh-performance liquid chromatography electrospray ionization Q-Orbitrap mass spectrometry for the analysis of 451 pesticide residues in fruits and vegetables: method development and validation. J Agric Food Chem 62:10375-10391

16. Zhang ZL, Rhind SM (2011) Optimized determination of polybrominated diphenyl ethers and polychlorinated biphenyls in sheep serum by solid-phase extraction-gas chromatography-mass spectrometry. Talanta 84:487-493 
17. Sapozhnikova Y, Lehotay SJ (2015) Review of recent developments and applications in low-pressure (vacuum outlet) gas chromatography. Anal Chim Acta 899:13-22

18. Han L, Sapozhnikova Y, Lehotay SJ (2016) Method validation for 243 pesticides and environmental contaminants in meats and poultry by tandem mass spectrometry coupled to low-pressure gas chromatography and ultrahigh-performance liquid chromatography. Food Control 66:270-282

19. Mastovska K, Lehotay SJ, Anastassiades M (2005) Combination of analyte protectants to overcome matrix effects in routine $\mathrm{GC}$ analysis of pesticide residues in food matrixes. Anal Chem 77:8129-8137

20. Mastovska K, Lehotay SJ (2004) Evaluation of common organic solvents for gas chromatographic analysis and stability of multiclass pesticide residues. J Chromatogr A 1040:259-272

21. Koesukwiwat U, Lehotay SJ, Leepipatpiboon N (2011) Fast, low-pressure gas chromatography triple quadrupole tandem mass spectrometry for analysis of 150 pesticide residues in fruits and vegetables. J Chromatogr A 1218:7039-7050

22. [SANTE/11945/2015] Guidance document on analytical quality control and method validation procedures for pesticides residues analysis in food and feed. http://ec.europa.eu/food/plant/docs/ plant_pesticides_mrl_guidelines_wrkdoc_11945_en.pdf

23. Klee MS, Blumberg LM (2002) Theoretical and practical aspects of fast gas chromatography and method translation. J Chromatogr Sci 40:234-247

24. Lehotay SJ (2007) Determination of pesticide residues in foods by acetonitrile extraction and partitioning with magnesium sulfate: collaborative study. J AOAC Int 90:485-520

25. Medina-Pastor P, Rodriguez-Torreblanca C, Andersson A, Fernandez-Alba AR (2010) European Commission proficiency tests for pesticide residues in fruits and vegetables. TrAC. Trends Anal Chem 29:70-83

26. Hajslova J, Zrostlikova J (2003) Matrix effects in (ultra)trace analysis of pesticide residues in food and biotic matrices. J Chromatogr A 1000:181-197

27. Erney DR, Gillespie AM, Gilvydis DM, Poole CF (1993) Explanation of the matrix-induced chromatographic response enhancement of organophosphorus pesticides during open tubular column gas chromatography with splitless or hot on-column injection and flame photometric detection. J Chromatogr 638:57-63 